\title{
Ageing via sexual perception is a by-product of male adaptive plasticity in
} Drosophila melanogaster.

$8{ }^{1}$ Ethology lab, Ethology, Ecology and Evolution group, Cavanilles Institute of Biodiversity and

9 Evolutionary Biology, University of Valencia, Valencia, Spain.

$11{ }^{2}$ Evolutionary Ecology lab, Ethology, Ecology and Evolution group, Cavanilles Institute of Biodiversity 12 and Evolutionary Biology, University of Valencia, Valencia, Spain.

$14{ }^{*}$ Corresponding author: q.corbel@live.fr

16 Keywords: Drosophila melanogaster, adaptive plasticity, phenotypic plasticity, ageing, sensory

17 perception, sexual selection, chemical cues

18 
ABSTRACT

22 Sensory perception of environmental cues can dramatically modulate ageing across distant taxa.

23 For example, male Drosophila melanogaster age faster if they perceive female cues but fail to mate

24 (ageing via sexual perception). This finding has been a breakthrough for our understanding of the mechanisms of ageing, yet we ignore how and why such responses have evolved. Here, we used $D$. melanogaster to ask whether ageing via sexual perception may be a by-product of plastic adaptive responses to female cues, and found that while long-term sexual perception leads to reproductive costs, short-term perception increases male lifetime reproductive success in a competitive environment. Simulations under a wide range of socio-sexual and demographic scenario suggest that such plasticity as a response to sexual perception might be a widespread strategy in nature. Finally, we show that sexual perception can significantly magnify sexual selection (15-27\% average increase in the opportunity for selection).

\section{INTRODUCTION}

35 Over the last decades, we have realised the potential for sensory perception to act as a modulator of ageing across invertebrate and vertebrate taxa (1-4). A series of ground-breaking studies have shown that sensory perception can trigger physiological changes at multiple levels, from homeostasis to tissue physiology, that significantly accelerate ageing $(3,5-8)$. For instance, chemosensory perception of food impairs the extended lifespan conferred by dietary restriction in both the vinegar fly Drosophila melanogaster (3) and in the nematode Caenorhabditis elegans $(1,9)$. Similarly, in these two model species, exposure to different types of conspecific cues decreases lifespan and alters critical physiological traits $(5,7,8,10)$, suggesting that ageing via sensory perception operates across distant taxa and functional contexts.

Organisms respond to environmental cues through a host of plastic physiological, anatomical or morphological changes that allow them to adjust their behaviour and life-history strategy so as to improve their fitness (11). For example, in some insect species, males respond to socio-sexual cues (i.e. density and diversity of rival male odours indicative of varying levels of sperm competition) by strategically adjusting their investment in sperm numbers, ejaculate components and/or post-copulatory mate guarding behaviour (e.g. 12-16). Plastic responses are also sometimes maladaptive and lead to a decrease in individual fitness. For example, stressful conditions or 
unreliable environmental cues can sometimes engender maladaptive plasticity $(17,18)$ and can possibly hinder the evolution of adaptive genotypes (19-20). Thus, in principle, ageing via sensory perception may result from either adaptive or maladaptive responses to environmental cues.

Because studies have so far primarily focused on identifying the mechanisms linking sensory perception to ageing, we simply ignore what selective pressures (if any) underlie this phenomenon. It has been suggested that long-term costs associated with sensory perception could be a byproduct of adaptive responses in the short-term (21), but the question of whether ageing via sensory perception bears an adaptive value remains unanswered.

Sexual perception (i.e. perception of reproductive opportunities) is a particularly interesting driver of ageing. Drosophila melanogaster males that do not regularly mate suffer significant physiological costs and a drastic reduction in survival as a sole consequence of perceiving female chemical cues $(5,7)$. In addition, long-term exposure to female chemical cues reduces male lifetime fitness in a competitive environment by approximately $25 \%$, mostly due to accelerated reproductive ageing (22). Given that nature showcases a wide range of sophisticated adaptive plastic responses to diverse and complex types of reproductive cues, understanding why sexual perception accelerates ageing and whether it bears an adaptive value may be of particular evolutionary interest. In addition, it has been suggested that ageing via sexual perception can magnify sexual selection $(22,23)$. Because ageing via sexual perception is contingent on a failure to mate, it will act to further decrease the fitness of males with inherently low mating success, thus potentially increasing the overall variance in male reproductive success (i.e. the opportunity for selection) and consequently the potential for sexual selection. Furthermore, if costs associated with long-term sexual perception are a by-product of adaptive short-term responses, sexual perception may similarly intensify sexual selection by increasing the inherent fitness advantage of high-quality (i.e. high probability of mating soon and acquiring sensory-mediated benefits) vs. low-quality (i.e. low probability of mating soon) males. Sexual selection is pivotal in driving male and female fitness, population viability, and evolvability (24-31), hence the need to address the potential role of ageing via sexual perception as a magnifier of sexual selection (23).

In this study, we first address the question of whether ageing via sensory perception can be adaptive by disentangling the fitness consequences of short vs. long-term sexual perception in $D$. melanogaster. We individually exposed males to females (treated males) while preventing access to females (experimentally simulating repeated failure to mate) for a period of $1,3,7$ or 15 days, thus artificially manipulating the onset of mating. We then compared the lifetime reproductive success 
83 of treated vs. controls when competing for a female against two rival males and found that male

84 lifetime fitness increased after a short-term exposure (1 day) to female cues, was neutral following

85 an intermediate exposure time ( 3 and 7 days), and only resulted in lower lifetime fitness following long-term exposure (15 days) to female cues. Rate-sensitive fitness analyses highlighted the importance of late-life reproduction (see 32,33 ) at modulating these effects, implying that both beneficial and costly plastic responses acquired through sensory perception are long-lasting. Next, we asked under what mating systems and demographic scenarios we may expect such male plasticity to evolve. We used the empirical results obtained to parameterize mathematical models and ran simulations under a wide range of socio-sexual contexts varying in mating rate (promiscuity), variability in male mating success (i.e. opportunity for sexual selection) and background population growth (i.e. demography). We found average mating rate to be the critical component for male plasticity to evolve, such that male plastic responses to female cues are favoured in promiscuous populations/species. Finally, we used these same simulations to estimate the degree to which male plastic responses in response to sexual perception may magnify sexual selection, and found that the opportunity for selection can be increased significantly (i.e. 15 to $27 \%$ average increase).

\section{RESULTS}

101 Reproductive success- While short-term sexual perception improved reproductive performances of 102 males (vs. controls), longer exposures lead to impaired reproductive performances, relative to 103 control flies (i.e. significant exposure $x$ treatment interaction in a LM: $F_{1,405}=4.81, P=0.029$; Figure

104 1). A population growth rate-sensitive analysis of fitness yielded qualitatively similar results, with a clear fitness advantage in the treatment group after 1 day of sexual perception across all population growth rates, but particularly so in a declining population (Figure 2a). This advantage mostly disappeared following 3 days and 7 days of sexual perception, except under markedly negative population growth rate (Figure $2 \mathrm{bc}$ ). Finally, longer exposures of 15 days and 21 days (21 days data taken from 22) showed clear fitness costs across all population growth rates, even more so in a declining population context (Figure 2de). Generally, the magnitude of the interaction between exposure time and treatment was strongest in a decreasing population demographic

112 scenario (relative to stable and growing population) and weakened with increasing growth rates 113 (Figure 2; see also SM). 
114 Survival - A Cox proportional hazards survival model revealed a significant exposure $\mathrm{x}$ treatment

115 interaction $\left(\operatorname{LR} \chi^{2}{ }_{1}=5.14, P=0.023\right)$.

116 Reproductive lifespan and reproductive ageing-We did not find significant effects on either

117 reproductive lifespan (i.e. treatment $x$ exposure effect, $L R \chi^{2}{ }_{1}=0.09, P=0.767$; sensory treatment

118 effect, $\operatorname{LR} \chi^{2}{ }_{1}=0.35, P=0.555$; exposure time effect, $\operatorname{LR} \chi^{2}{ }_{1}=0.145, P=0.704$ ) or reproductive ageing

119 (using net decrease in male relative reproductive success between the first and the second female

120 they competed over -henceforth $\Delta{ }_{q_{1}}{ }_{q_{2}}-, F_{1,393}=0.22, P=0.636$; using net decrease in male

121 relative reproductive success between the first and the third female they competed over -

122 henceforth $\left.\Delta Q_{1} Q_{3^{-}}, F_{1,359}=1.38, P=0.240\right)$. Sensory treatment had no effect on reproductive

123 ageing (using $\Delta{ }{ }_{1}{ }{ }_{2}: F_{1,393}=0.33, P=0.569$; using $\Delta{ }{ }_{1}{ }{ }_{3}: F_{1,359}=2.00, P=0.158$ ), but exposure

124 time significantly affected reproductive ageing $\left(\Delta q_{1}{ }_{q_{2}}: F_{1,393}=7.56, P=0.006\right.$; using $\Delta{ }{ }_{1}{ }{ }_{3}: F_{1,359}$

$125=8.80, P=0.003$ ) as the decrease in relative reproductive success over the course of two (and three)

126 females was of higher magnitude with increasing exposure (see SM for further details).

127 Model and simulations- We built a computer model to estimate male fitness based on the

128 assumptions that (1) the log-reproductive function $(\mathrm{I}(\mathrm{x}) \mathrm{m}(\mathrm{x})$; standard demographic notation)

129 modelling realized reproductive lifespan (i.e. from the onset of mating ( $\beta$ ) onwards) is a 90-degree

130 rotated sigmoid curve (i.e. monotonously decreasing, levelling-off at intermediate ages) and that

131 (2) the elevation (E) of that curve declines linearly with $\beta$. The features and additional details of our

132 computer model were largely based on the fitting of ad hoc Generalized Additive Models to our

133 empirical results. Another assumption of the computer model is that (3) the relationship between $\mathrm{E}$

134 vs. $\beta$ differs according to two alternative strategies: a) a "spendthrift" strategy (henceforth $S$

135 strategy), characterised by males that always respond as if perceiving female cues (i.e. always

136 engage the physiological responses associated with perception of reproductive opportunities), and

137 b) a "thrifty" strategy (henceforth $T$ strategy), characterised males that never respond to female

138 cues (i.e. never engage the physiological responses associated with perception of reproductive

139 opportunities; see SM for further detail). Note that presence/absence of female cues is irrelevant

140 to both these strategies, as they are unconditional fixed strategies. Our aim with these simulations

141 was to explore what conditions favour the expression of the $S$ fixed phenotype vs. the $T$ fixed

142 phenotypes vs. the evolution of a plastic phenotype that could display either of $S$ or $T$. In our

143 simulations, a randomly sampled $\beta$ was assigned to each individual, and this allowed us to compute

144 the effects of the $S$ and $T$ strategies on within-male population variation in fitness. We explored the 
$145 S$ and $T$ strategies in scenarios resulting from the combination of three factors: (1) daily population

146 growth rate $(r:-0.1,0,0.1)$, (2) mean value of $\beta$ (from 1 to $15 d$ ), and (3) standard deviation of $\beta$ ( $\sigma_{\beta}$ :

$1470.01,0.1,1 d)$. We envision mean $\beta$ as a direct consequence of female density, and we assume

148 standard deviation of $\beta$ to be correlated to the heritable variation in male mating performance.

149 The effect of the mean value of $\beta$ on simulated fitness followed a pattern tightly consistent with

150 variation in $E$ (Figure 3). This points out the prevalent role of $E$ in mediating the effect of $\beta$ on

151 fitness. Our simulations showed that the $S$ strategy was advantageous (compared to the $T$ strategy)

152 whenever mean $\beta$ was lower than 7-8 days, and disadvantageous for higher mean $\beta$ (Figure 3).

153 More precisely, within a range of $\beta$ between 1 to 7-8 days, the relative advantage of the $S$ strategy

154 increased with decreasing mean $\beta$. Contrastingly, within a range of $\beta$ between 8 to 15 days, the

155 disadvantage the $S$ strategy increased with increasing mean $\beta$. Standard deviation in male fitness

156 declined steeply with mean $\beta$ with the $S$ strategy, and was rather independent of mean $\beta$ with the $T$

157 strategy. This results in the $S$ strategy leading to higher fitness variation than the $T$ strategy for

158 mean $\beta$ lower than 7-8 days, but causing lower fitness variation for mean $\beta$ higher than 7-8 days.

159 For example, in a stationary population $(r=0)$, fitness was higher for the $T$ strategy ( $38 \%$ in

160 average) across average mean $\beta$ equal or above 7 days. Contrastingly fitness was lower for the $T$

161 strategy (35\% in average) across average mean $\beta$ below 7 days. With respect to the increase in male

162 fitness variation (i.e. opportunity for selection), we found that responding to female cues (i.e.

163 plastic male strategy switching between the $S$ and the $T$ strategies accordingly to what strategy is

164 advantageous) resulted in an overall average increase in standard deviation of 15 to $27 \%$. Within-

165 population standard variation in onset of mating (male mating rate; i.e. a proxy for variation in male

166 quality and hence starting opportunity for selection) had little effect on mean fitness and standard

167 deviation of fitness, so estimates above are given for the median across the whole range explored

168 (see SM). These patterns are qualitatively the same for the population growth rates and the

169 standard deviation of $\beta$ explored in all simulations (see SM for further details).

\section{DISCUSSION}

172 In this study, we found evidence strongly suggesting that the so far reported ageing effects induced

173 by male perception of female cues in fact derive from adaptive male plastic responses. Sensing

174 female cues for a short period of time (1 day) prior to reproduction triggered plastic responses in

175 males that made them better competitors, and ultimately increased their lifetime reproductive 
success. Perception of female cues was neutral following intermediate exposures (between 3 and 7 days) and only resulted in net fitness costs if males perceived females for at least 15 days of simulated reproductive failure. Simulations showed that such plastic response can be advantageous under a wide range of socio-sexual and demographic contexts and significantly increase the opportunity for selection, and thus the intensity of sexual selection.

We found that, in Drosophila melanogaster, short-term (1 day) sensory exposure to female cues (simulating a short lag between perception of reproductive opportunities and the onset of mating) increases male lifetime reproductive success in a biologically relevant context (i.e. in competition against rival males over a series of different females; Figure 1). In contrast, we did not find evidence of net perception effects for intermediate sensory exposure treatments simulating a lag of $3 d$ and $7 d$ between the perception of reproductive opportunities and the onset of mating. Finally, and in line with previous evidence, we found that extended exposure to female cues prior to mating (i.e. $15 \mathrm{~d}$ lag) led to net fitness costs in $D$. melanogaster males $(5,7,22)$. Such fitness costs were due to a decrease in reproductive success (see also 22) but, contrarily to previous studies $(5,7,22)$, we did not find that sexual perception reduced survival. This is likely due to the fact that our longest exposure (15 days) was considerably shorter than those in previous studies $($ see $5,7,22)$. To summarise, these results show that sexual perception is beneficial if males rapidly access mating after perceiving reproductive opportunities, and that sexual perception only leads to net fitness costs and accelerated ageing in males when the lag between perception of reproductive opportunities and the onset of mating is relatively long (i.e. 15 days long or more).

As population demography modulates the relative importance of reproductive timing (3235), we complemented our analysis by calculating the rate-sensitive fitness consequences of male exposure to female cues. Our rationale was both to assess fitness effects in a range of demographic backgrounds and to examine the relative importance of early-versus late-life reproduction at modulating the aforementioned effects of sexual perception. While qualitatively similar across population dynamics, we found the potential for sexual perception to affect individual fitness to be more marked in decreasing populations, across all exposure lengths (Figure 2). Given that late-life reproduction is more important in decreasing populations, relative to stable or increasing populations $(34,35)$, this result highlights that sexual perception effects accumulate through life. Interestingly, post-hoc exploration of the data indicated that benefits linked to short-term (1d) 
perception were rapidly observable (as soon as over the 24 hours following the onset of mating)

and persisted over the whole life of males (see SM for further details), implying that the

physiological changes triggered by early-on perception of female cues were conserved in the long

211 term. In other words, males do not seem to experience transient changes, but rather long-lasting

212 responses that impact their life history. This is, in itself, a remarkable finding, and we suggest a

213 priority for future studies should be to address the mechanism underlying this phenomenon.

214 Understanding what specific fitness benefits (e.g. pre- vs. post-copulatory competition) are

215 involved in these effects might offer valuable information about reproduction-survival trade-offs

216 and the evolution of ageing.

melanogaster males in nature, and available evidence strongly suggests it will. Virgin $D$.

melanogaster females generally mate soon when presented to males, with average mating rates of one mating every 1 to 3 days in lab and wild populations (36-43). This implies that, despite strong male-male pre-copulatory competition and high variance in male mating success (44), most of the males that will ever reproduce are likely to start mating within their first two weeks of life. However, the aforementioned mating rates reflect situations of relatively high density that are more likely to represent maximum mating rates rather than to be indicative of average mating rates over space and time in the wild. While little is known about fine-grained population density dynamics in wild D. melanogaster (45), there is indirect evidence to suggest that density fluctuations are probably common in the field. This species' ecology is closely linked to food sources (e.g. orchards) whose availability exhibits drastic spatiotemporal variation, which is inevitably bound to modulate local density. Accordingly, in the field $D$. melanogaster larvae maintain a stable polymorphism (largely driven by a single locus - the for gene-) with two foraging variants: a) rovers, characterized by long foraging trips and pupation away from the food source, are preferentially selected under high densities, while b) sitters, characterized by short foraging trips and pupation in the food source, are preferentially selected in low densities (46-47). Thus, there is suggestive evidence that natural populations of this species are subject to frequent fluctuations in local density. Under low densities and/or during phases where dispersal in search of food sources is likely to be common, finding (and mating with) females may be less frequent. This implies that average mating rates in the wild are almost certainly variable, as a consequence of fluctuations in local density. Under this context, male plastic responses such as those reported in this study are 
240 likely to be adaptive because they will allow males to engage the physiological machinery that

241 allows them to maximize their competitive ability, but only in the presence of socio-sexual cues

242 indicative of mating opportunities. Thus, a plastic response based on the presence of reliable socio-

243 sexual cues seems to allow males to accrue the benefits of engaging in responses that condition

244 them for competition over reproduction when in a high-density scenario, while avoiding the long-

245 term costs that would ensue from unconditionally engaging such responses in a low-density

246 environment.

A wealth of evidence has already accumulated to show that sensory cues, from nutritional to social cues, can profoundly modulate ageing in taxa as distant as flies and worms (21), but what do we know about their functional significance? It has been suggested that sensory modulation of ageing may result from a trade-off whereby organisms respond to ecologically relevant environmental cues to maximise early-life fitness at the expense of late-life fitness (21). However, we know little about the specific adaptive value of such plastic responses, and scarcely anything about what contexts we may expect these mechanisms to evolve in. In the case of ageing via sexual perception, an interesting facet of the costs involved in male plastic responses of this sort is that they are contingent on mating, so that costs are only paid if there is a relatively long lag between male perception of reproductive opportunities and the onset of mating $(5,7,22)$. This has important implications for both the evolution of this strategy and its impact on related evolutionary processes. We suggest that male plastic behaviour similar to that reported here for $D$. melanogaster will arise frequently in nature in response to fluctuations in the availability of reproductive opportunities, whenever these correlate reliably with environmental cues (e.g. female odours). Implicit in this hypothesis are two predictions. First, that such changes must be, on average, beneficial to males facing imminent competition over reproduction, as strongly suggested by our results. Second, that male plastic responses should give rise to long-term physiological costs (Caenorhabditis elegans; 10 ) and flies (D. melanogaster; 5,7 ), suggesting that this phenomenon may be evolutionary conserved across the tree of life (3). Our simulations further show that male plastic 
272 mating rate, as captured by the average $\beta$ (onset of mating) in our simulations, to be the main

273 determinant for the evolution of male plastic responses to reproductive cues. Consistently high

274 mating-rates benefited a fixed "spendthrift" (i.e. always respond as if females were present)

275 strategy (30-85\% fitness advantage for mating rates of one every 1 to 4 days), while consistently

276 low mating rates benefited a "thrifty" (i.e. always respond as if females were absent) strategy (38-

$27756 \%$ fitness advantage for mating rates of one every 12 to 14 days; see SM for further details). In

278 contrast, a plastic response would have higher fitness whenever average mating rates vary within

279 an intermediate range of mating rates (Figure 4). Thus, we predict that in species where average

280 mating rates are consistently high, such as promiscuous species with little fluctuation in density, a

281 fixed spendthrift strategy will be favoured (Figure 4). This will be the case of species with very short

282 lifespans, where long-term costs are likely to be negligible (mayflies are a good, albeit quite

283 extreme, example). In contrast, we predict that a fixed thrifty strategy will be favoured in species

284 with consistently low mating rates (Figure 4), such as iteroparous species with low density and/or

285 prolonged reproductive seasons. Finally, male plastic responses are expected to evolve in species

286 where mating rates fluctuate in accordance with changes in population density (Figure 4). Given

287 that environmental stochasticity effects on population density are very frequent, we suggest that

288 plastic responses to sexual perception, such as those reported here, might actually be a common

289 strategy in nature; at least in promiscuous species with reproductive lifespans and demographic

290 parameters within the range of $D$. melanogaster (modelled in this study), which are typical of many

291 insects. Our model shows that under the latter condition, male plastic behaviour will be favoured

292 almost irrespective of population demography (i.e. growth rate) and inter-individual variability in

293 male mating rates. We thus suggest a priority for future studies should be to study the

294 phenomenon of ageing via sexual perception across species with contrasting life histories.

A second implication of the fact that male plasticity costs are contingent on mating is that

297 this phenomenon can magnify sexual selection. The idea is that male responses to sexual

298 perception can magnify sexual selection by further reducing the reproductive success of low-quality

299 males. Briefly, if perception costs result from a decoupling between perceived and realised mating

300 opportunities, it follows that low-condition males will tend to disproportionally pay such costs

301 simply because they have lower mating success, and hence will take longer to mate $(22,23)$. In

302 addition to this, our results suggest that males able to mate soon after perceiving female cues

303 accrue a lifetime reproductive advantage over rival males. Given that high-quality males (i.e. good 
304 at intra-sexual competition) will tend to mate quicker than the average male, this means they are

305 expected to disproportionally harvest perception benefits. As a consequence, male plastic

306 responses to female cues are bound to increase the overall variability in male reproductive success

307 (i.e. opportunity for selection), hence potentially magnify sexual selection beyond previously

308 surmised. Our simulations show that this modulation can be biologically meaningful, with an

309 average increase in the opportunity for selection estimated of between 15 and $27 \%$ for the whole

310 range of average mating rates explored (Figure 4 \& SM). Given that plastic male responses to

311 female cues are expected to be favoured in promiscuous species, where sexual selection is already

312 expected to be intense, this could lead to eco-evolutionary feedback that further magnifies sexual 313 selection.

\section{MATERIALS AND METHODS}

\section{Stocks and maintenance}

317 Unless when stated otherwise, all flies used in this experiment were laboratory wild type (wt)

318 Dahomey D. melanogaster. We used homozygous recessive spa mutants (sparkling poliert) as

319 competing males and reproducing females in order to assess paternity of focal wt individuals.

320 Homozygous spa flies have a distinguishable rough-eye phenotype that allowed us to distinguish all

321 offspring from our focal males, and have the added advantage of being slightly worse competitors

322 than wt males, which ensured focal males would eventually mate. Stock populations are

323 maintained outbred, with overlapping generations, at $25^{\circ} \mathrm{C}$ on a $12 \mathrm{~h} \mathrm{light} / 12 \mathrm{~h}$ dark cycle fed with

324 standard food (solidified aqueous mix containing $60 \mathrm{~g} . \mathrm{L}^{-1}$ corn flour, $50 \mathrm{~g} . \mathrm{L}^{-1}$ white sugar, $40 \mathrm{~g} \cdot \mathrm{L}^{-1} \mathrm{fresh}$ 325 baker's yeast, 10g.L $\mathrm{L}^{-1}$ soy flour, $10 \mathrm{~g} . \mathrm{L}^{-1}$ industrial agar, 3g. $\mathrm{L}^{-1}$ Methyl 4-hydroxybenzoate (nipagin),

$32610 \mathrm{~mL} . \mathrm{L}^{-1} 96 \% \mathrm{EtOH}, 5 \mathrm{~mL} . \mathrm{L}^{-1} 99 \%$ propionic acid). We obtained all flies by collecting eggs on yeasted 327 grape juice agar plates (FlyStuff grape agar premix, Genesee Scientific) from stock populations. We 328 reared all flies used in this experiment at a controlled density of ca. 200 individuals per $250 \mathrm{~mL}$ 329 bottle filled with ca. $75 \mathrm{~mL}$ of food, and isolated them by sex within 6 hours of emergence (i.e. as 330 virgins) at standard densities of 15 females and 20 males per vial, using ice anaesthesia.

\section{Experimental design}

333 We individually exposed wt males to either donor females (treatment) or not (control) following 334 the method as described in García-Roa et al. (22). Briefly, we connected two vials containing food 
335 to each other and placed a mesh partition between them. Males were then singly isolated on one

336 side of the mesh, while the other contained either: a) three wt females (i.e. treated males) or b) no

337 females (i.e. control). This mounting allowed treated males to be exposed to female odours while

338 ensuring they would not mate. To explore whether sensory perception effects are contingent on

339 the time of exposure to female cues, we exposed experimental males to sensory stimuli (i.e. female

340 cues or control) for one day, three days, seven days or 15 days; $n=60$ per treatment combination

341 (i.e. 2 treatments * 4 exposure times * 60 biological replicates, for a total of 480 focal flies). This

342 replicate number was determined based on the effect size obtained in a prior experiment (22)

$\$ 43$ exploring the effects of sexual perception on reproductive success.

Immediately following sensory exposure treatments, we transferred focal males into vials in which they competed over a spa female against two spa males for the rest of their lifetime (all four

347 flies were virgin at the beginning of assays). During this time, we checked for survival daily and 348 replaced competitors and females that died before our focal male by virgin individuals of the same 349 age. We also swapped competitors and females for younger virgin individuals (less than 12 days 350 old) every 10-11 days to simulate a natural situation, where males have to compete for different 351 females over their lifetime. We transferred flies into new vials every 3-4 days, and incubated vacant 352 vials for 12 days (time needed to ensure all viable flies have emerged, given that average 353 generation time is 8 to 9 days), before freezing them at $-20^{\circ} \mathrm{C}$ for later counting of $w t$ and $s p a$ F1 354 offspring. Treatment allocation was masked during counting. For transfer of flies from one vial to 355 another one, we used gentle $\mathrm{CO}_{2}$ anaesthesia. All steps of the experiments were performed at $35625^{\circ} \mathrm{C}$.

\section{Statistical significance analyses}

359 We used Cox proportional hazards (48) for survival and post-hoc reproductive lifespan analyses, 360 checking assumptions using statistical and graphical diagnostics based on Schoenfeld residuals (49). 361 We fitted a general linear model (LM) in order to analyse relative reproductive success (using $362 w t /$ total number of F1 - \#F1-).To analyse reproductive ageing, we first calculated the average 363 reproductive success of each focal male over each one of the first three females it competed for 364 (only for individuals surviving this period of time). Then, we calculated the net decrease in male relative reproductive success between the first and the second female $\left(\Delta q_{1}{ }_{2}\right)$, as well as 
between the first and the third female $\left(\Delta q_{1} Q_{3}\right)$. We fitted general linear models to $\Delta q_{1}{ }_{q_{2}}$ and $\Delta Q_{1} \mathrm{Q}_{3}$

All these models incorporated treatment (categorical variable, two levels: sensory sexual perception and control), exposure time (continuous variable) and the interaction between treatment and exposure as fixed factors. We checked model assumptions (residuals normality, homoscedasticity, homogeneity of variances, absence of outliers and influential points, absence of autocorrelation of factors) using the "performance" package (50). We assessed model term significance with $\alpha=0.05$. Models were run computing type III ANOVA using the "car" package (51), in R studio 1.1.456. No clear outlier was detected in the dataset, and no datapoint was excluded of statistical analyses. All significant reported p-values remain so after correcting for inflation of type I error rate due to multiple testing (using the Benjamini-Hochberg procedure for a false discovery rate of 0.05$)$.

In order to place lifetime reproductive success effects in a demographic context, we additionally estimated individual rate-sensitive fitness estimates of treated versus control individuals across exposures (1, 3, 7 and 15 days) for different population growth rates $(r=-0.1$, $0.05,0,0.05$ and $0.1 ; 32,33,52)$. For the latter analysis, we included results from García-Roa et al. (22) as a historical treatment/control, as this study used the same experimental design as well as the same lab population of flies, but with a sensory perception exposure time of 21 days.

\section{Modelling and simulations}

Following Tatar \& Promislow (53) we define fitness as the integration over age from $x=0$ to $\omega$ (the end of reproductive ages) of

$$
\exp (-r x) k(x)
$$

390 where $r$ is the intrinsic growth rate, and $k(x)$ is the so called reproductive function $(I(x) m(x)$; i.e.

391 survival times fertility at age x; e.g. 33). Additionally, $x=0$ is the age at maturity, so that

392 developmental times are not considered to make a difference when fitness is compared between

393 scenarios or individuals. Our computer simulation model is informed by our experimental design,

394 but making the biological mechanisms as explicit as possible and using directly interpretable factors 395 that act on $\mathrm{k}(\mathrm{x})$. In this way, the values of model parameters can be obtained from the estimates 396 from experimental data. 
Therefore, in order to build our computer simulation model, we performed data analysis to describe and extract model components. In that analysis, $\mathrm{k}(\mathrm{x})$ was analysed on an individual basis; i.e., $k_{i}(x)$, where $i$ identifies the $i^{\text {th }}$ experimental individual. The realized $k_{i}(x)$ is a count; i.e., the number of offspring at age $x$ (i.e. from $x$ to $x+\Delta_{x} x$; the subscript stresses that the experimental time lag between consecutive observations is not constant) of the individual $\mathrm{i}^{\text {th }}$. Commonly in Mixed Effects Models the expectation of the log-count is modelled additively; in our case

$$
u_{i}(x)=\log _{e}\left(k_{i}(x)\right) \text {, for } k_{i}(x)>0 .
$$

As $u_{i}(x)$ may be a rather complex function, we used Generalized Additive Models (GAMs).

We assumed a negative binomial (NB) error distribution and applied GAM separately for each experimental condition (four treatments and four controls). In addition to a structural relationship between $u_{i}(x)$ and $x$ (a more or less elevated smooth function to be found), our GAM analysis assumed two random components (random slope and random intercept; both following uncorrelated Gaussian distributions) to account for among-individual variation in the experiments. We used packages mgcv (54) and nlme (55). GAMs found smooth functions (expected $\left.u_{i}(x) v s . x\right)$ with similar shapes (approximately, an asymmetric a 90-degree rotated sigmoid curve) for the eight experimental conditions (see SM for further details. The shape was compressed for the life window with potential access to females; that is, between the onset of access to females (B; 1, 3, 7 and 15 days) and the end of the reproductive life. The rotated sigmoid functions were more or less elevated depending on the experimental condition, and we found a clear pattern whereby elevation decreases with the female access onset. Using least squares, we fitted lines (treatment and control separately) to the relationship between the elevation and the female access onset (E vs. B). Our GAMs did not find random intercepts to be significant but did find a significant variation

After this analysis, for our computer model the $\mathrm{i}^{\text {th }}$ individual is assumed to have the expected $\exp \left(u_{i}(x)\right)$ (i.e. randomness from NB distribution was neglected). Our computer model uses the functional shape showed in SM with the elevation describes by SM). However, in order to compute elevation of $u_{i}(x)$ now the mating onset is $\beta$ (not $B$, fixed experimentally) and is a log-normal variable with values assigned randomly to males. Additionally, a male-dependent Gaussian random slope is added to get $u_{i}(x)$. We envisage the random slope as being due to demographic stochasticity, and assumed it to be independent on the timing of the mating onset. Simulations 
429 10; Wolfram Research, Inc.). Additional technical details and parameter values are provided in the 430 SM.

\section{ACKNOWLEDGEMENTS}

435 We thank Claudia Londoño, Alejandro Hita and Mariona Vinyeta for help with experimental set up, 436 data collection and data entering, respectively.

DATA AVAILABILITY

439 Dataset uploaded to Dryad repository url: https://doi.org/10.5061/dryad.sn02v6x3w

\section{AUTHORS' CONTRIBUTIONS}

442 QC, RG-R and PC conceived and designed the study. QC conducted the experiment with help from 443 RG-R and PC. QC analysed the data. MS conceived the theoretical framework for the mathematical 444 models with help from PC. MS built the mathematical models and ran the simulations. QC and PC 445 wrote the manuscript with input from MS and RG-R. All authors approved the final version of this 446 manuscript. Authors declare no competing interests. 
bioRxiv preprint doi: https://doi.org/10.1101/2021.04.19.440494; this version posted April 21, 2021. The copyright holder for this preprint (which was not certified by peer review) is the author/funder, who has granted bioRxiv a license to display the preprint in perpetuity. It is made available under aCC-BY 4.0 International license.

PC was supported by a "Ramon y Cajal" fellowship (RYC-2013-12998). RG-R, QC and the work

described here were supported by a Plan Nacional research grant (CGL2017-89052-P) to PC.

RG-R was also supported by a "Juan de la Cierva Formación" Research Fellowship (FJC2018-037058-

I; Ministerio de Ciencia, Innovación y Universidades - Spanish Government).

\section{References}

1. J. Apfeld, C. Kenyon, Regulation of lifespan by sensory perception in Caenorhabditis elegans. Nature 402(6763), 804-809 (1999).

2. J. Alcedo, C. Kenyon, Regulation of $C$. elegans longevity by specific gustatory and olfactory neurons. Neuron 41, 45-55 (2004).

3. S. Libert, J. Zwiener, X. Chu, W. VanVoorhies, G. Roman, S.D. Pletcher, Regulation of Drosophila life span by olfaction and food-derived odors. Science 315, 1133-1137 (2007).

4. C.E. Riera, M.O. Huising, P. Follett, M. Leblanc, J. Halloran, R. Van Andel, C.D. de Magalhaes Filho, C. Merkwirth, A. Dillin, TRPV1 pain receptors regulate longevity and metabolism by neuropeptide signaling. Cell 157(5), 1023-1036 (2014).

5. C.M. Gendron, T.-H. Kuo, Z.M. Harvanek, B.Y. Chung, J.Y. Yew, H.A. Dierick, S.D. Pletcher, Drosophila life span and physiology are modulated by sexual perception and reward. Science 343, 544-548 (2014).

6. M.J. Waterson, B.Y. Chung, Z.M. Harvanek, I. Ostojic, J. Alcedo, Pletcher S. Water sensor ppk28 modulates Drosophila lifespan and physiology through AKH signaling. Proceedings of the national academy of sciences 22, 8137-8142 (2014).

7. Z.M. Harvanek, Y. Lyu, C.M. Gendron, J.C. Johnson, S. Kondo, D.E.L. Promislow, S.D. Pletcher, Perceptive costs of reproduction drive ageing and physiology in male Drosophila. Nature ecology and evolution 1, 0152 (2017).

8. T.S. Chakraborty, M.C. Gendron, Y. Lyu, A.S. Munneke, M.N. DeMarco, Z.W. Hoisington, S.D. Pletcher, Sensory perception of dead conspecifics induces aversive cues and modulates lifespan through serotonin in Drosophila. Nature communications 10(1), 2365 (2019).

9. E. D. Smith, T. L. Kaeberlein, B. T. Lydum, J. Sager, K. L. Welton, B. K. Kennedy, M. Kaeberlein, Age- and calorie-independent life span extension from dietary restriction by bacterial deprivation in Caenorhabditis elegans. BMC developmental biology 8, 49 (2008). 
11. B. Demmig-Adams, M.R. Dumlao, M.K. Herzenach, W.W. III Adams, Acclimation. In Behavioral Ecology (Jørgensen S.E. and Fath B.D. eds.) 15-23, Elsevier, Oxford (2008).

12. M.J. Gage, Risk of sperm competition directly affects ejaculate size in the Mediterranean fruit fly. Animal behaviour 42(6), 1036-1037 (1991).

13. L.W. Simmons, Sperm competition and its evolutionary consequences in the insects. Princeton, NJ, Princeton University Press (2001).

14. P. Carazo, E. Font, B. Alfthan, Chemosensory assessment of sperm competition levels and the evolution of internal spermatophore guarding. Proceedings of the royal society B 274, 261-267 (2007).

15. S. Lüpold, M.K. Manier, O. Ala-Honkola, J.M. Belote, S. Pitnick, Male Drosophila melanogaster adjust ejaculate size based on female mating status, fecundity, and age. Behavioral ecology 22(1), 184-191 (2011).

16. J. Morimoto, G.C. McDonald, E. Smith, D.T. Smith, J.C. Perry, T. Chapman, T. Pizzari, S. Wigby, Sex peptide receptor-regulated polyandry modulates the balance of pre- and post-copulatory sexual selection in Drosophila. Nature Communications 10, 283 (2019).

17. T.J deWitt., A. Sih, D.S. Wilson, Costs and limits of phenotypic plasticity. Trends in ecology \& evolution 13(2), 77-81 (1998).

18. C.K. Ghalambor, J.K. McKay, S.P. Carroll, D.N. Reznick, Adaptive versus non-adaptive phenotypic plasticity and the potential for contemporary adaptation in new environments. Functional ecology 21(3), 394-407 (2007).

19. M. van Kleunen, M. Fischer, Constraints on the evolution of adaptive phenotypic plasticity in plants. New phytologist 166, 49-60 (2005).

20. J. Merilä, A.P. Hendry, Climate change, adaptation, and phenotypic plasticity: the problem and the evidence. Evolutionary applications 7, 1-14 (2013).

21. N.J. Linford, T.-H. Kuo, T.P. Chan, S.D. Pletcher, Sensory perception and aging in model systems: from the outside in. Annual review of cell and developmental biology 27, 759-785 (2011).

22. R. García-Roa, M. Serra, P. Carazo, Ageing via perception cost of reproduction magnifies sexual selection. Proceedings of the Royal society B 285, 20182136 (2018).

23. P. Carazo, R. García-Roa, Z. Sultanova, M. Serra, Perception costs of reproduction can magnify sexual selection. Nature Ecology \& Evolution 1, 1414-1415 (2017).

24. M.J. West-Eberhard, Sexual selection, social competition, and speciation. The quarterly review of biology 58(2), 155-183 (1983). 
25. D.K. McLain, M.P. Moulton, T.P. Redfearn, Sexual selection and the risk of extinction of introduced birds on oceanic islands. Oikos 74, 27-34 (1995).

26. P.D. Lorch, S. Proulx, L. Rowe, T. Day, Condition dependent sexual selection can accelerate adaptation. Evolutionary ecology research 5, 867-881 (2003).

27. U. Candolin, J. Heuschele, Is sexual selection beneficial during adaptation to environmental change? Trends in ecology and evolution 23, 446-452 (2008).

28. M. Jarzebowska, J. Radwan, Sexual selection counteracts extinction of small populations of the bulb mites. Evolution 64, 1283-1289 (2010).

29. A.J Lumley, L. Michalczyk, J.J. Kitson, L.G. Spurgin, C.A. Morrison, J.L. Godwin, M.E. Dickinson, O.Y. Martin, B.C. Emerson, T. Chapman, M.J. Gage, Sexual selection protects against extinction. Nature 522: 470-473 (2015).

30. C. Martinez-Ruiz, R.J. Knell, Sexual selection can both increase and decrease extinction probability: reconciling demographic and evolutionary factors. Journal of animal ecology $\mathbf{8 6}, \mathbf{1 1 7 -}$ 127 (2016).

31. J.G. Cally, D. Stuart-Fox, L. Holman, Meta-analytic evidence that sexual selection improves population fitness. Nature communications 10, 2017 (2019).

32. B. Charlesworth, Selection in populations with overlapping generations. 1. The use of Malthusian parameters in population genetics. Theoretical population biology 1, 352-370 (1970).

33. B. Charlesworth, Evolution in age-structured populations. Cambridge University Press, Cambridge (1994).

34. J.B McGraw., H. Caswell, Estimation of individual fitness from life-history data. The American naturalist 147, 47-64 (1996).

35. T.G. Benton, A. Grant, Evolutionary fitness in ecology: comparing measures of fitness in stochastic, density-dependent environments. Evolutionary ecology research 2,769-789 (2000).

36. L. Partridge, A. Hoffmann, J.S. Jones, Male size and mating success in Drosophila-Melanogaster and Drosophila-Pseudoobscura under field conditions. Animal Behavior 35, 468-476 (1987).

37. M.H. Gromko, T.A. Markow, Courtship and remating in field populations of Drosophila. Animal Behavior 45: 253-262 (1993).

38. L.G. Harshman, A.G. Clark, Inference of sperm competition from broods of field-caught Drosophila. Evolution 52(5): 1334-1341 (1998).

39. M. Imhof, B. Harr, G. Brem, C. Schlötterer. Multiple mating in wild Drosophila melanogaster revisited by microsatellite analysis. Molecular ecology 7(7), 917-917. (1998). 
40. B. Jones, A.G. Clark, Bayesian sperm competition estimates. Genetics 163, 1193-1199 (2003).

41. T.J. Giardina, A.G. Clark, A.C. Fiumera, Estimating mating rates in wild Drosophila melanogaster females by decay rates of male reproductive proteins in their reproductive tracts. Molecular ecology resources 17 (6): 1202-1209. 2017.

42. L. Soto-Yéber, J. Soto-Ortiz, P. Godoy, R. Godoy-Herrera, The behavior of adult Drosophila in the wild. PLoS One 13, e0209917 (2018).

43. R. Dukas. Natural history of social and sexual behavior in fruit flies. Scientific reports 10, 21932. (2020).

44. A. Joshi, M.H. Do, L.D. Mueller, Poisson distribution of male mating success in laboratory populations of Drosophila melanogaster. Genetical research 73, 239-249 (1999).

45. C.J. Reaume, M.B. Sokolowski, The nature of Drosophila melanogaster. Current biology 16 (16): 623-628. DOI: 10.1016/j.cub.2006.07.042. (2006).

46. M.B. Sokolowski, Foraging strategies of Drosophila melanogaster: a chromosomal analysis. Behavior genetics 10(3), 291-302 (1980).

47. M.B Sokolowski., H.S. Pereira, K. Hughes, Evolution of foraging behavior in Drosophila by density-dependent selection. Proceedings of the national academy of sciences $94(14), 7373-7377$ (1997).

48. D.R. Cox, Regression models and life-tables. Journal of the Royal Statistical Society. Series B (Methodological) 34(2), 187-220 (1972).

49. D. Schoenfeld, Partial residuals for the proportional hazards regression model. Biometrika 69(1), 239-241 (1982).

50. D. Lüdecke, D. Makowski, P. Waggoner, I. Patil, Performance: Assessment of Regression Models Performance. CRAN. (2020).

51. J. Fox, S. Weisberg, An R Companion to Applied Regression, Third edition. Sage, Thousand Oaks CA. (2019).

52. D.A. Edward, C. Fricke, D.T. Gerrard, T. Chapman, Quantifying the life-history response to increased male exposure in female Drosophila melanogaster. Evolution 65(2), 564-573 (2010).

53. M. Tatar, D.E. Promislow, Fitness costs of female reproduction. Evolution 51, 1323-1326 (1997).

54. S.N. Wood, Fast stable restricted maximum likelihood and marginal likelihood estimation of semiparametric generalized linear models. Journal of the Royal Statistical Society B 73(1), 3-36 (2011) 
636 55. J. Pinheiro, D. Bates, S. DebRoy, D. Sarkar, R Core Team, nlme: Linear and Nonlinear Mixed

637 Effects Models. R package version 3.1-149 (2020)

638

639

640

641

642

643

644

645

646

647

648

649

650

651

652

653

654

655

656

657

658

659

660

661

662

663

664

665

666

667

668

669

670

671

672

673

674 


$$
\begin{aligned}
& \text { control } \\
& \text { treatment }
\end{aligned}
$$

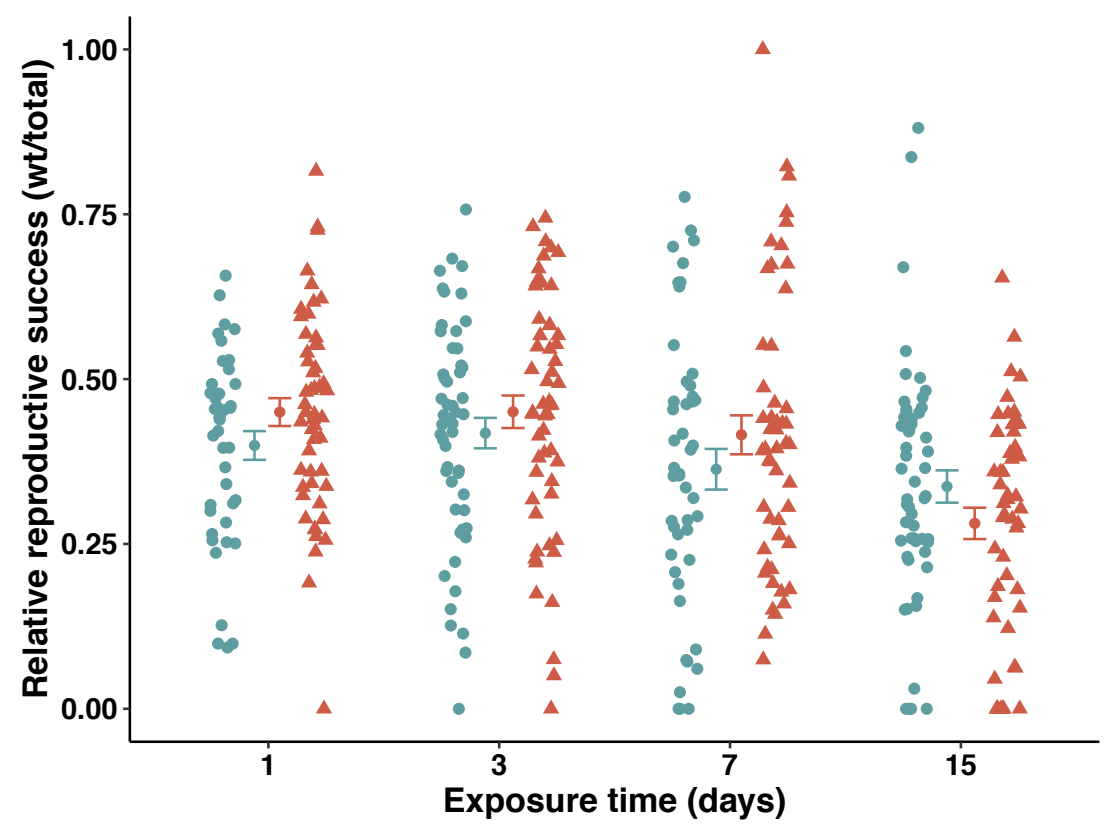

677 Figure 1: Relative lifetime reproductive success (percentage of offspring fathered by the focal male)

678 after 1 day, 3 days, 7 days and 15 days exposure to the sensory treatment or control. Orange

679 triangles represent treated males and green circles represent control males. Inwards these single

680 observations are displayed means \pm SEM. To avoid superposition of the datapoint belonging to

681 different experimental conditions, control and treatment datapoints of the same exposure were

682 presented separated from each other on continuous $\mathrm{x}$ axis. 

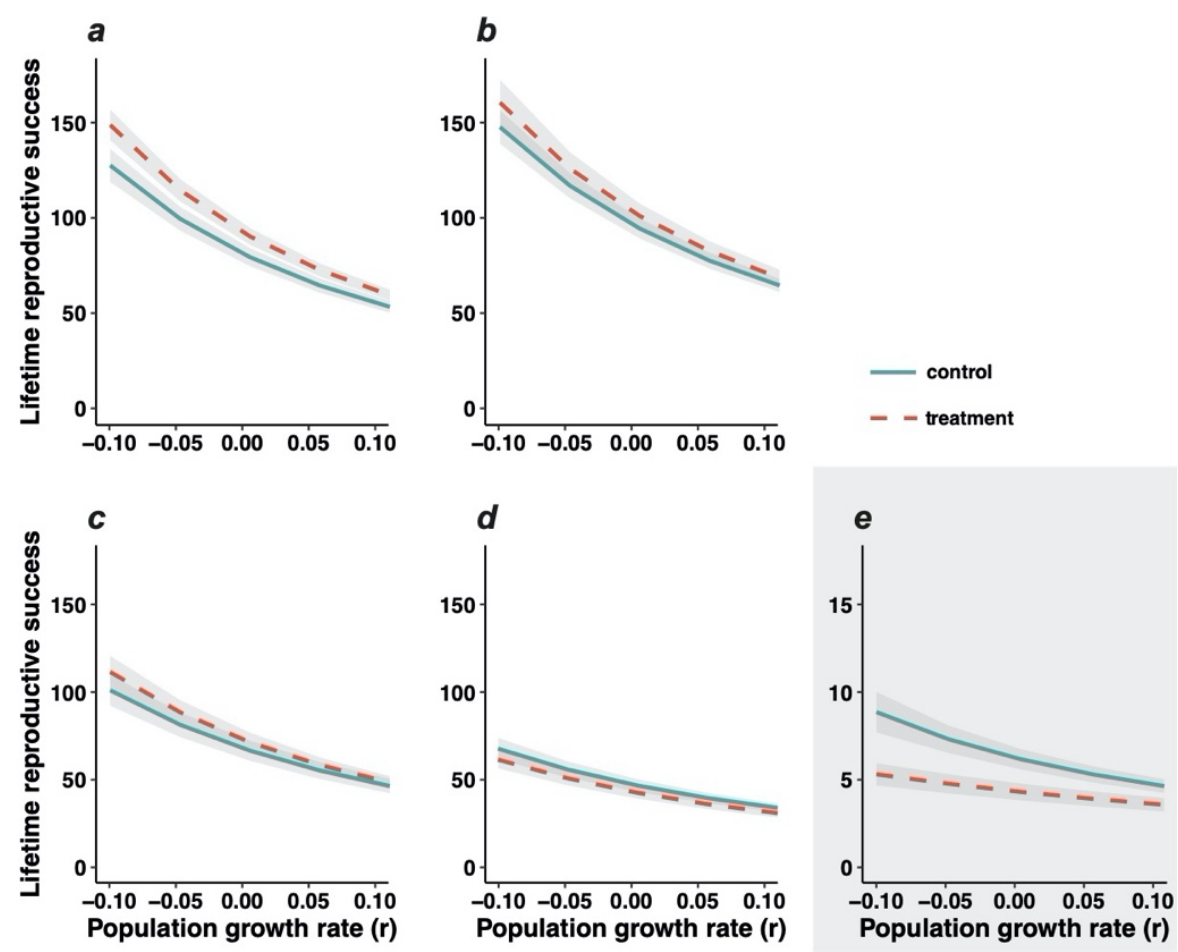

685 Figure 2: Average lifetime reproductive success of treated (red dashed line) versus control (green 686 continuous line) males as a function of population growth rate, after 1 day, 3 days, 7 days, 15 days 687 and 21 days of exposure to female conspecifics $(\boldsymbol{a}, \boldsymbol{b}, \boldsymbol{c}, \boldsymbol{d}, \boldsymbol{e}$, respectively; $\boldsymbol{e}$ after García-Roa et al. 688 (22)). Lines are linear interpolations between means computed for each population growth rate.

689 The greyed area represents the standard error around the mean. $\boldsymbol{e}$ is included to provide context.

690 Because flies were older when provided access to mating, average fitness is considerably lower, 691 regardless of the treatment. Therefore, the response variable (lifetime reproductive success) is 692 downscaled by 10. 

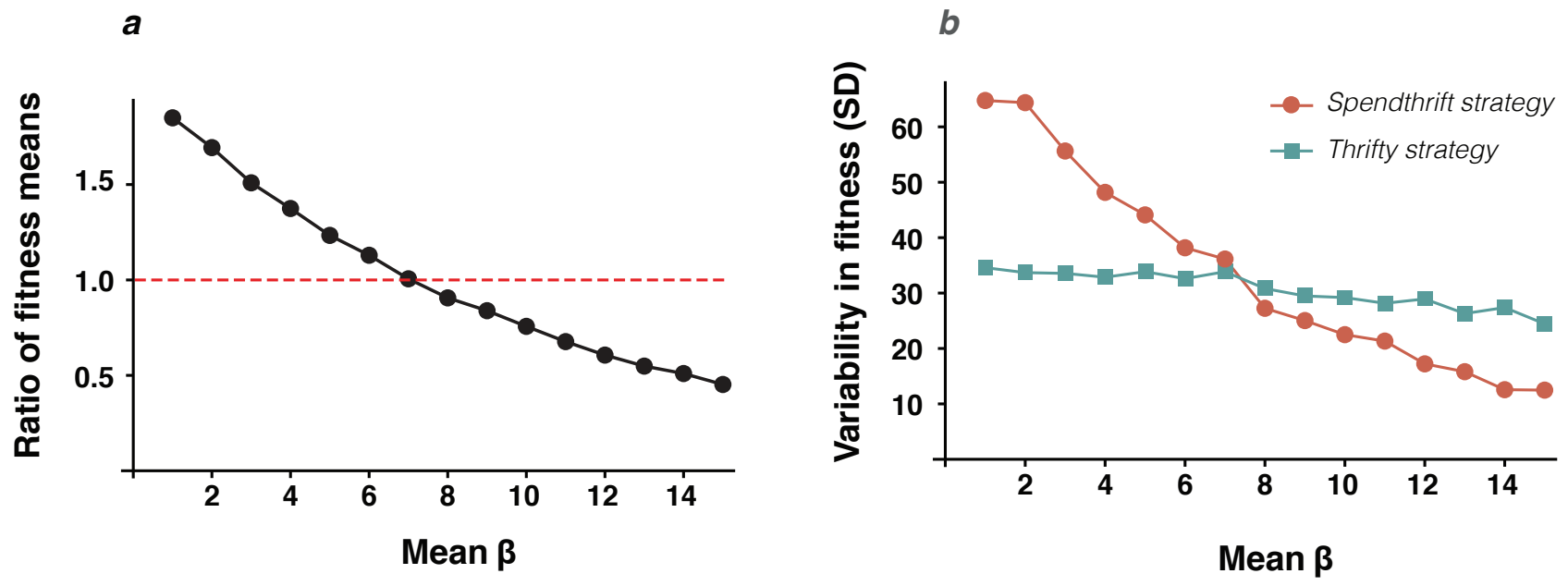

Figure 3. Ratio between male fitness means (a) and male fitness standard deviations (b) for simulated fly males across values of mean $\beta$ (age of mating onset). Here the simulation portrays a growing population $(r=0.1$ ) with standard deviation of $\beta=1$ and sample size $n=10000$. In $(a)$, y values above one represents an advantage of the spendthrift strategy over the thrifty strategy, whereas values below one represent a disadvantage of the spendthrift strategy over the thrifty strategy. 


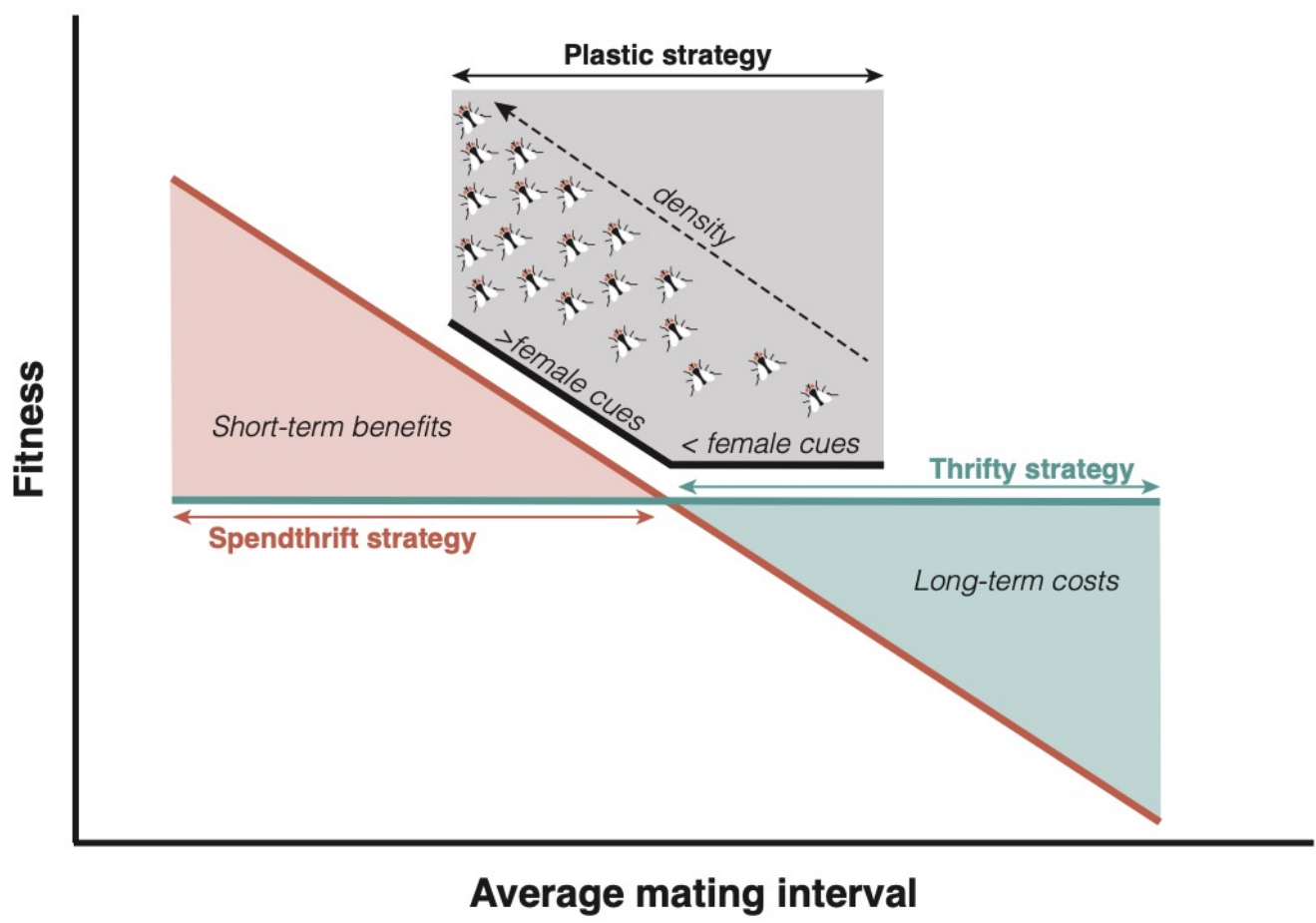

722 Figure 4: Alternative male strategies favoured depending on the range of variation in mating rates 723 experienced by the population. Average mating rates that are consistently high will favour a fixed

724 "spendthrift" strategy that taps on the short-term benefits of engaging a maximum male 725 physiological response in preparation to competition for reproduction. In turn, average mating 726 rates that are consistently low will favour a fixed "thrifty" strategy that avoids the long-term costs of engaging a maximum male physiological response in preparation to competition for reproduction. Finally, variation in mating rates within a low-to-moderate range (i.e. uncertainty as to whether males will be, on average, quick or slow to mate) will favour plastic male strategies whereby males engage (or not) maximum physiological responses depending on the presence of

731 female cues (i.e. local mating patch density). This analysis assumes that local mating patch density correlates positively with average mating rates in the mating patch. 
bioRxiv preprint doi: https://doi.org/10.1101/2021.04.19.440494; this version posted April 21, 2021. The copyright holder for this preprint (which was not certified by peer review) is the author/funder, who has granted bioRxiv a license to display the preprint in perpetuity. It is made available under aCC-BY 4.0 International license. 
754 Supplementary 1. Table displaying F-statistic and $P$-value of the exposure*treatment interaction for 755 population growth-rates ranging from -0.1 to 0.1 . Only exposure times ranging from 1 to 15 days 756 were used in this analysis. The exposure*treatment interaction is clearer at negative growth-rate 757 than it is at positive growth-rate. This demonstrate that late-life reproduction is of crucial 758 importance in the effects observed.

759

\begin{tabular}{cccccc}
\hline & \multicolumn{5}{c}{ Population growth-rate $(\boldsymbol{r})$} \\
\cline { 2 - 6 } & $\boldsymbol{r = - 0 . 1}$ & $\boldsymbol{r}=-\mathbf{0 . 0 5}$ & $\boldsymbol{r}=\mathbf{0}$ & $\boldsymbol{r}=\mathbf{0 . 0 5}$ & $\boldsymbol{r}=\mathbf{0 . 1}$ \\
\hline $\boldsymbol{F}_{(\mathbf{3}, \text { 405) }}$ & 2.545 & 2.462 & 2.287 & 2.087 & 1.897 \\
$\boldsymbol{P}$-value & 0.056 & 0.062 & 0.078 & 0.102 & 0.130 \\
\hline
\end{tabular}



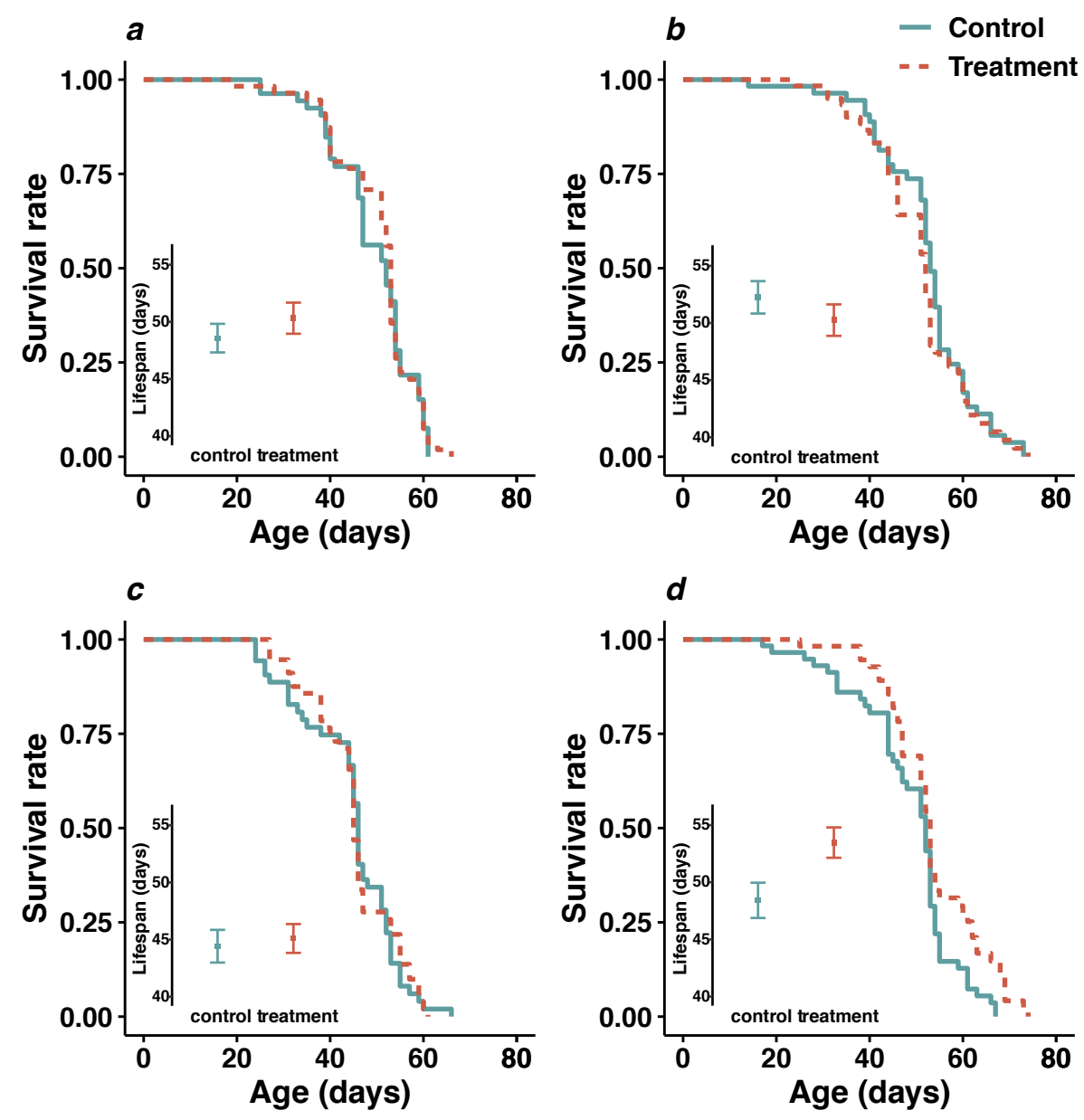

788 Supplementary 2. Survival rate as a function of age and average lifespan of treated and control

789 individuals following 1 day (a), 3 days (b), 7 days (c) and 15 days (d) exposure. The orange dashed

790 line represents the survival of treated males and the green continuous line represent the survival of

791 control males. Green and orange squares depict the average lifespan of treated and control males,

792 respectively, and vertical bars represent the standard errors around the average lifespan. 

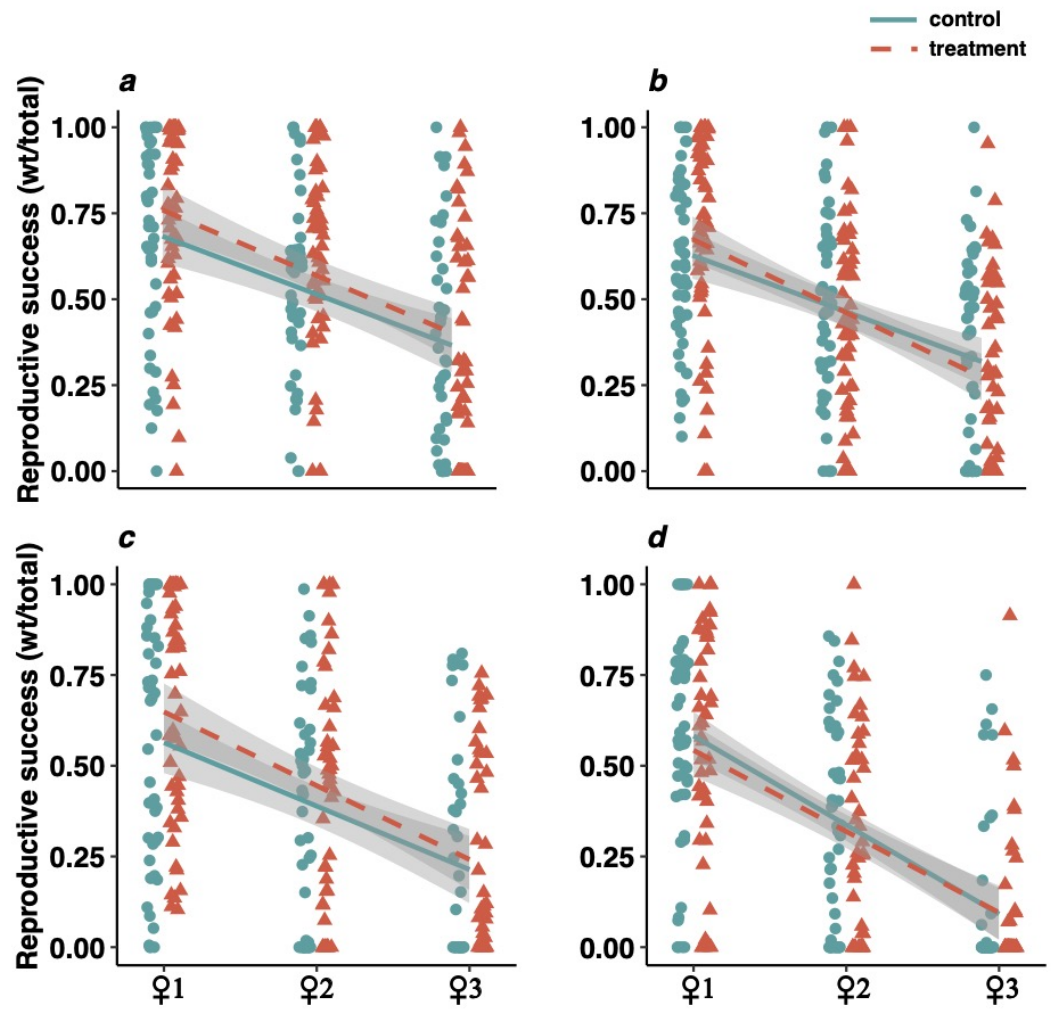

794 Supplementary 3. Relative reproductive success (percentage of offspring fathered by the focal

795 male) of treated and control males, following 1 day (a), 3 days (b), 7 days (c) and 15 days (d)

796 exposure, for the first three females they were competing over. Each orange triangle represents an

797 observation of a treated male (with sexual perception) relative reproductive success over a female

798 (12 days), while green circles are for control males. The linear regression lines represent the rate of

799 decrease in relative reproductive success with the orange dashed line corresponding to treated

800 males (and the green continuous line is the regression corresponding to control males, over the

801 first three females they were competing over. Greyed areas around the regression lines represent

$80295 \%$ confidence intervals. 
bioRxiv preprint doi: https://doi.org/10.1101/2021.04.19.440494; this version posted April 21, 2021. The copyright holder for this preprint

(which was not certified by peer review) is the author/funder, who has granted bioRxiv a license to display the preprint in perpetuity. It is made available under aCC-BY 4.0 International license.

806

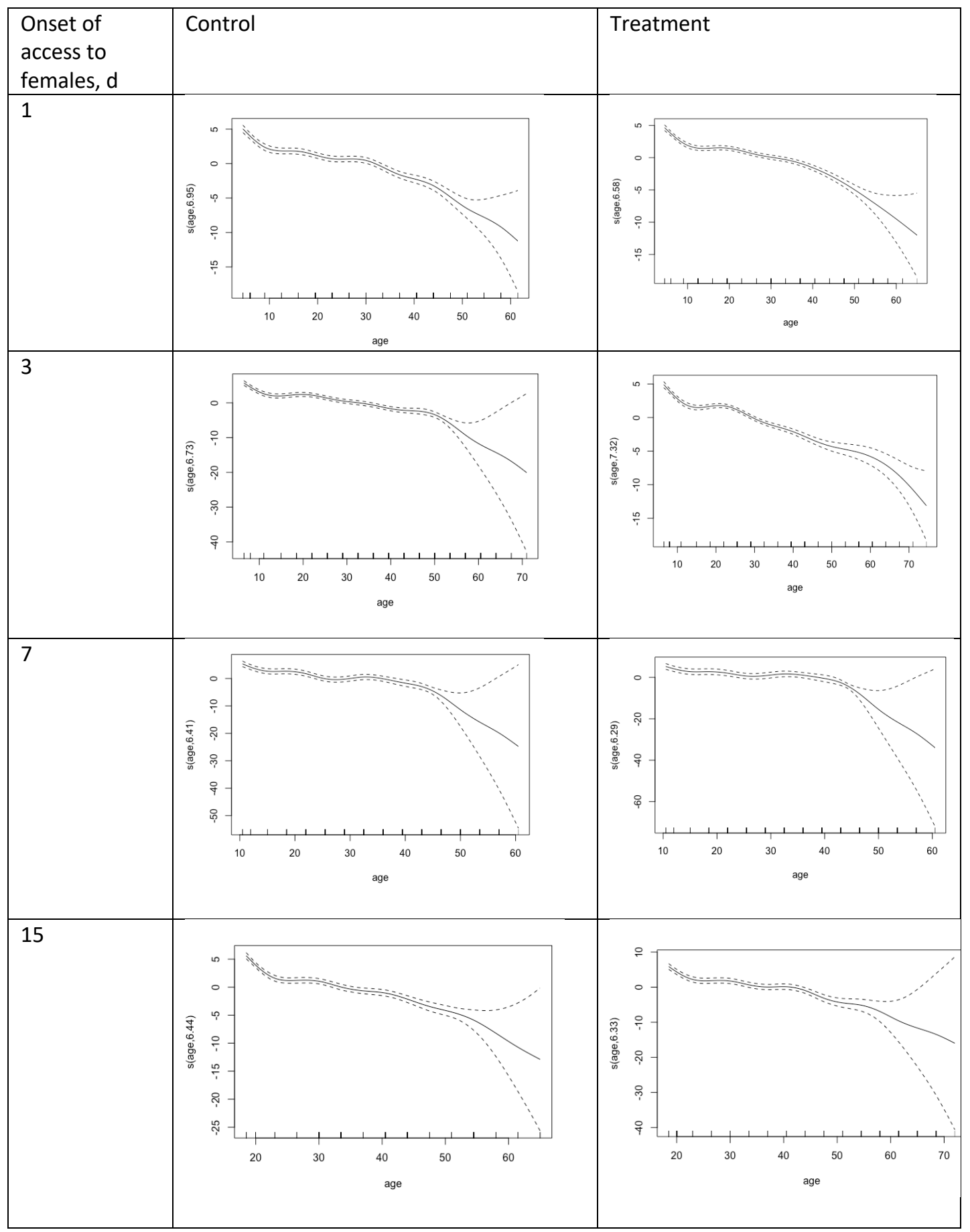

808 Supplementary 4. Smooth functions found by GAM and the shape of log-reproductive function for

809 female sensing males (treatment) and control males, across exposure times $(1,3,7,15$ days) 
bioRxiv preprint doi: https://doi.org/10.1101/2021.04.19.440494; this version posted April 21, 2021. The copyright holder for this preprint (which was not certified by peer review) is the author/funder, who has granted bioRxiv a license to display the preprint in perpetuity. It is made available under aCC-BY 4.0 International license.

812

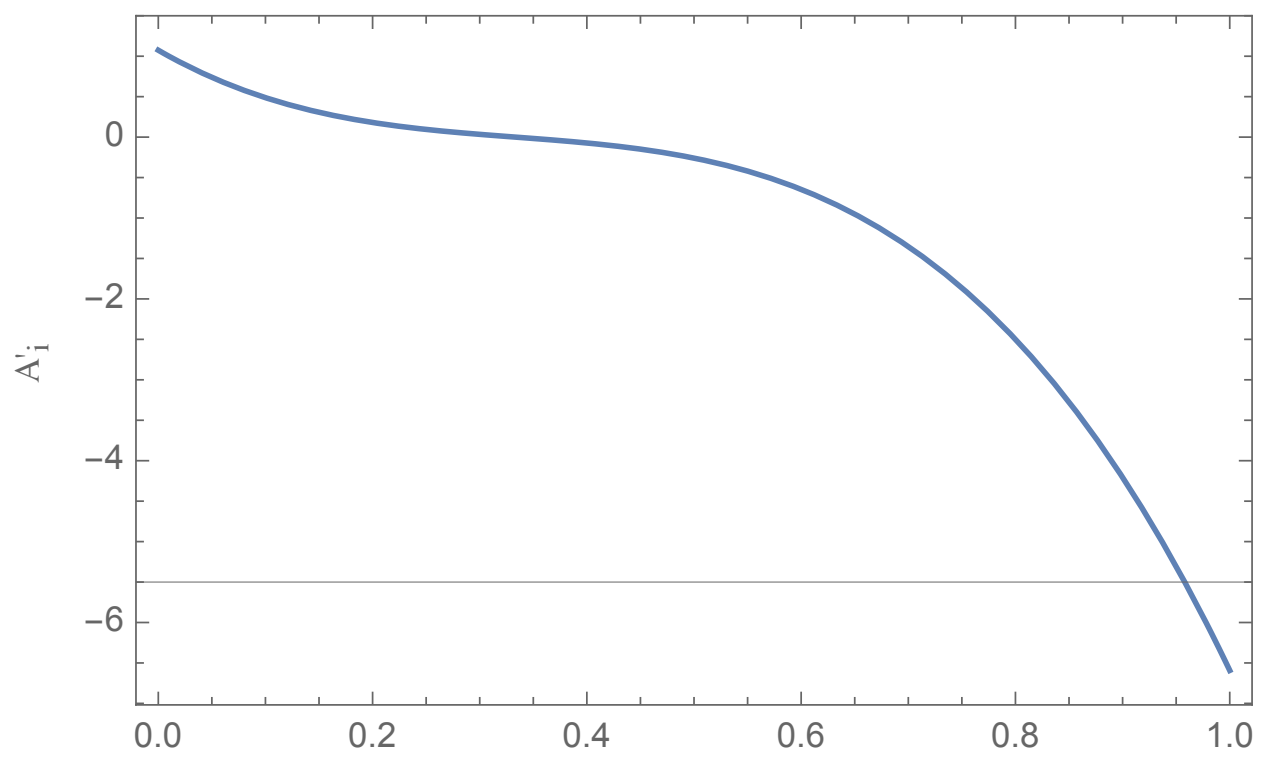

$\mathrm{X}^{\prime}$

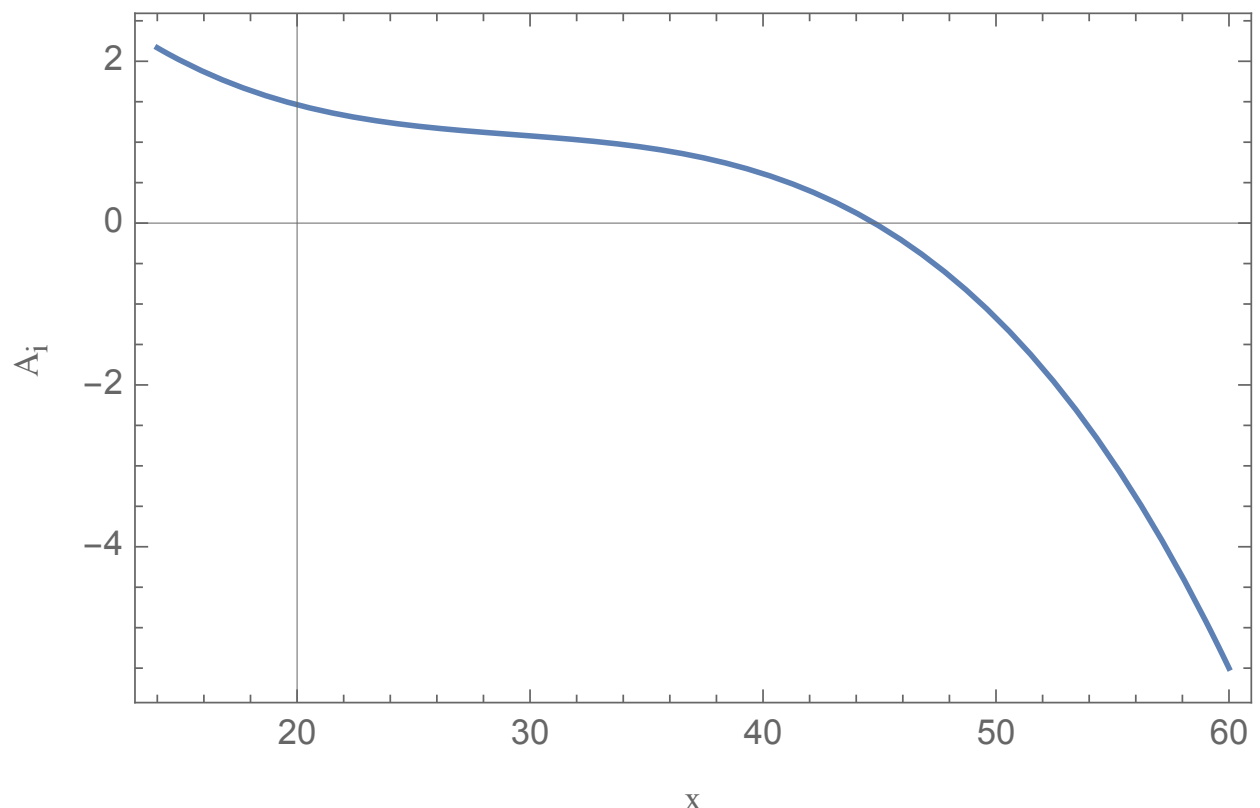

815 Supplementary 5. Log-reproductive function. The showed shape is assumed in the computer model

816 for the structural component of the log-reproductive function. Upper panel, core function (before

817 rescaling; $b 1=-1 ; b 3=-20 ; c=1 / 3$. Lower panel, rescaled function for the case $\beta_{i}=14$ and $\omega=60$;

818 note that the average value for the function in the realized range is equal to zero. The structural

819 part of the log-reproductive function is completed by adding a constant value, the elevation (E). In

820 order to get the log-reproductive function of a male, a linear component with random slope is

821 added. 


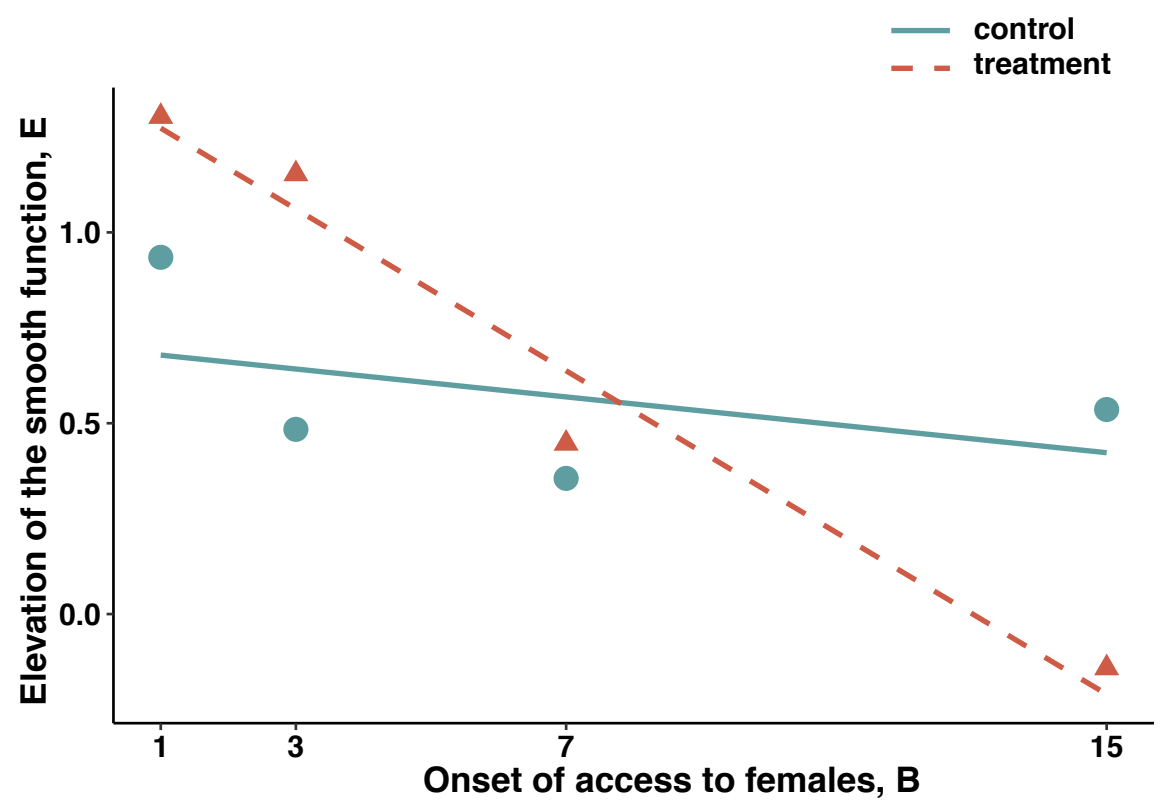

825 Supplementary 6. Relationship between the elevation (E) of the smooth function found after GAM

826 and the experimentally controlled onset of access to females ( $B$, age in days). Lines fitted using LS

827 regression. Treatment: $E=-0.11 B+1.379, R^{2}=0.96, P=0.019$. Control: $E=-0.02 B+0.699, R^{2}=$

$8280.21, \mathrm{P}=0.546$. These lines were used in our simulations to model the "spendthrift" and "thrifty"

829 strategies, respectively, but substituting B (access to females; experimentally fixed, common to any

830 male) for $\beta$ (mating onset; randomly chosen from a lognormal distribution for each simulated

831 individual).

832 
834

835

836

837

838

839

840

841

842

843

844

845

846

847

848

849

850

851

852

853

854

855

856

857

858

859

860

861

862

863

864

865

866

867

868

869

870

871

872

873

874

875

876

877

878

879

880

Supplementary 7. Computer model components and values

\begin{tabular}{|c|c|c|}
\hline Symbol & Concept & Value(s) \\
\hline$\beta_{i}$ & Age of mating onset of the $\mathrm{i}^{\text {th }}$ individual & $\begin{array}{l}\text { randomly chosen } \\
\text { (lognormal } \\
\text { distribution) }\end{array}$ \\
\hline$\omega$ & Age of reproductive end & 60 \\
\hline$k_{i}(x)$ & $\begin{array}{l}\text { Reproductive function of the } i^{\text {th }} \text { individual, } \\
l_{i}(x) m_{i}(x)^{a}\end{array}$ & derived \\
\hline$u_{i}(x)$ & $\begin{array}{l}\text { Log-reproductive function, } \\
\log _{e}=k_{i}(x)\end{array}$ & derived \\
\hline$E_{i}$ & Elevation of $u_{i}(x)$ & derived \\
\hline$A_{i}$ & $\begin{array}{l}\text { Centred shape of the log reproductive } \\
\text { function }\end{array}$ & $\begin{array}{l}\text { derived, see } \\
\text { supplementary } 5 \text { for } \\
\text { parameters }\end{array}$ \\
\hline$S_{i}$ & $\begin{array}{l}\text { Slope of the additive individual component } \\
\text { for the log-reproductive function }\end{array}$ & $\begin{array}{l}\text { randomly chosen } \\
\text { (Gaussian } \\
\text { distribution) }\end{array}$ \\
\hline$\sigma_{\mathrm{s}}$ & Standard deviation of $\mathrm{s}_{\mathrm{i}}$ & 0.05 \\
\hline$e_{0}$ & $\begin{array}{l}\text { Intercept of the line used to compute } E_{i} \\
\text { from } \beta_{i}=0\end{array}$ & $\begin{array}{l}1.4 \text { (“spendthrift") } \\
0.7 \text { (“thrifty") }\end{array}$ \\
\hline $\mathrm{e}_{1}$ & $\begin{array}{l}\text { Slope of the line used to compute } E_{i} \text { from } \\
\beta_{i}=0\end{array}$ & $\begin{array}{l}-0.12 \text { (“spendthrift") } \\
-0.02 \text { ("thrifty") }\end{array}$ \\
\hline$\sigma_{\beta}$ & Standard deviation of $\beta_{i}$ & $0.01,0.1,1$ \\
\hline r & Daily population growth rate & $-0.1,0,0.1$ \\
\hline-- & Mean $\beta_{i}$ & $1,2, \ldots 15$ \\
\hline
\end{tabular}


bioRxiv preprint doi: https://doi.org/10.1101/2021.04.19.440494; this version posted April 21, 2021. The copyright holder for this preprint

(which was not certified by peer review) is the author/funder, who has granted bioRxiv a license to display the preprint in perpetuity. It is made available under aCC-BY 4.0 International license.

883 Supplementary 8 . Simulation results for the two replicates that assumed $r$ (daily growth rate) $=0$ 884 and standard deviation of mating onset (in days) $=1$. Each replicate is based on $n=10000$ males. 885

$$
\text { Growth rate }(r): 0
$$

Standard deviation for the age at first mating (in days): 1

\begin{tabular}{|c|c|c|c|c|c|c|c|}
\hline \multirow[b]{2}{*}{ Replicate } & \multirow{2}{*}{$\begin{array}{c}\text { AFM. } \\
\text { d }\end{array}$} & \multirow{2}{*}{$\begin{array}{c}\text { Fitness Ratio } \\
(\mathrm{S} / \mathrm{T})\end{array}$} & \multicolumn{5}{|c|}{ Standard deviation of fitness } \\
\hline & & & spendthrift $(S)$ & thrifty $(T)$ & plastic $(P)$ & ratio $\mathrm{P} / \mathrm{S}$ & ratio $P / T$ \\
\hline \multirow[t]{17}{*}{ A } & 1 & 1.81 & 468.94 & 273.07 & 468.94 & 1.00 & 1.72 \\
\hline & 2 & 1.65 & 468.06 & 298.29 & 468.06 & 1.00 & 1.57 \\
\hline & 3 & 1.51 & 623.00 & 271.01 & 623.00 & 1.00 & 2.30 \\
\hline & 4 & 1.35 & 370.02 & 329.45 & 370.02 & 1.00 & 1.12 \\
\hline & 5 & 1.22 & 361.75 & 324.46 & 361.75 & 1.00 & 1.11 \\
\hline & 6 & 1.10 & 391.32 & 358.11 & 391.32 & 1.00 & 1.09 \\
\hline & 7 & 0.99 & 274.83 & 276.22 & 276.22 & 1.01 & 1.00 \\
\hline & 8 & 0.94 & 331.03 & 275.08 & 275.08 & 0.83 & 1.00 \\
\hline & 9 & 0.85 & 260.81 & 294.15 & 294.15 & 1.13 & 1.00 \\
\hline & 10 & 0.73 & 220.73 & 323.61 & 323.61 & 1.47 & 1.00 \\
\hline & 11 & 0.66 & 198.71 & 338.03 & 338.03 & 1.70 & 1.00 \\
\hline & 12 & 0.62 & 188.47 & 311.06 & 311.06 & 1.65 & 1.00 \\
\hline & 13 & 0.56 & 195.30 & 313.96 & 313.96 & 1.61 & 1.00 \\
\hline & 14 & 0.51 & 187.23 & 295.92 & 295.92 & 1.58 & 1.00 \\
\hline & 15 & 0.45 & 160.72 & 347.16 & 347.16 & 2.16 & 1.00 \\
\hline & & average & 313.39 & 308.64 & 363.89 & 1.16 & 1.18 \\
\hline & & summation & 4700.90 & 4629.60 & 5458.28 & 1.16 & 1.18 \\
\hline \multirow[t]{3}{*}{ B } & 1 & 1.85 & 501.55 & 266.97 & 501.55 & 1.00 & 1.88 \\
\hline & 2 & 1.67 & 464.34 & 292.73 & 464.34 & 1.00 & 1.59 \\
\hline & 3 & 1.52 & 434.55 & 267.71 & 434.55 & 1.00 & 1.62 \\
\hline
\end{tabular}


bioRxiv preprint doi: https://doi.org/10.1101/2021.04.19.440494; this version posted April 21, 2021. The copyright holder for this preprint

(which was not certified by peer review) is the author/funder, who has granted bioRxiv a license to display the preprint in perpetuity. It is made available under aCC-BY 4.0 International license.

349.42

375.61

308.11

297.30

255.65

231.52

260.77

192.49

197.70

191.86

157.31

135.73

290.26

320.92

368.64

1.27

1.15

4353.90

$329.35 \quad 349.42 \quad 1.00 \quad 1.06$

$\begin{array}{llll}276.05 & 375.61 \quad 1.00 \quad 1.36\end{array}$

$282.70 \quad 308.11$

1.00

1.09

$299.56 \quad 297.30$

$\begin{array}{ll}1.00 & 0.99\end{array}$

$305.09 \quad 305.09$

$1.19 \quad 1.00$

$425.80 \quad 425.80$

$1.84 \quad 1.00$

$319.82 \quad 319.82$

$1.23 \quad 1.00$

$349.56 \quad 349.56$

$376.27 \quad 376.27$

$1.90 \quad 1.00$

$323.00 \quad 323.00$

1.68

1.00

$347.12 \quad 347.12$

2.21

1.00

352.11

352.11

2.59

1.00

summation

4813.86

5529.66

1.27

1.15

86

888

889

890

92

893

895 


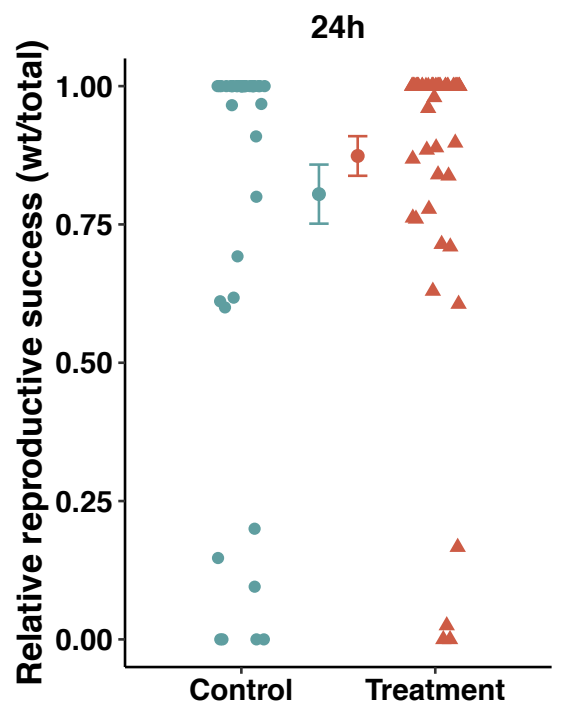

897 Supplementary 9. Mean relative reproductive success of control (green circles) vs treatment

898 (orange triangles) males over the first 24 hours of competition for reproduction against two rival

899 males for access to female, with the onset of access to female manipulated to 1 day. Vertical bars

900 represent the standard error around the mean

901

902

903

904

905

906 


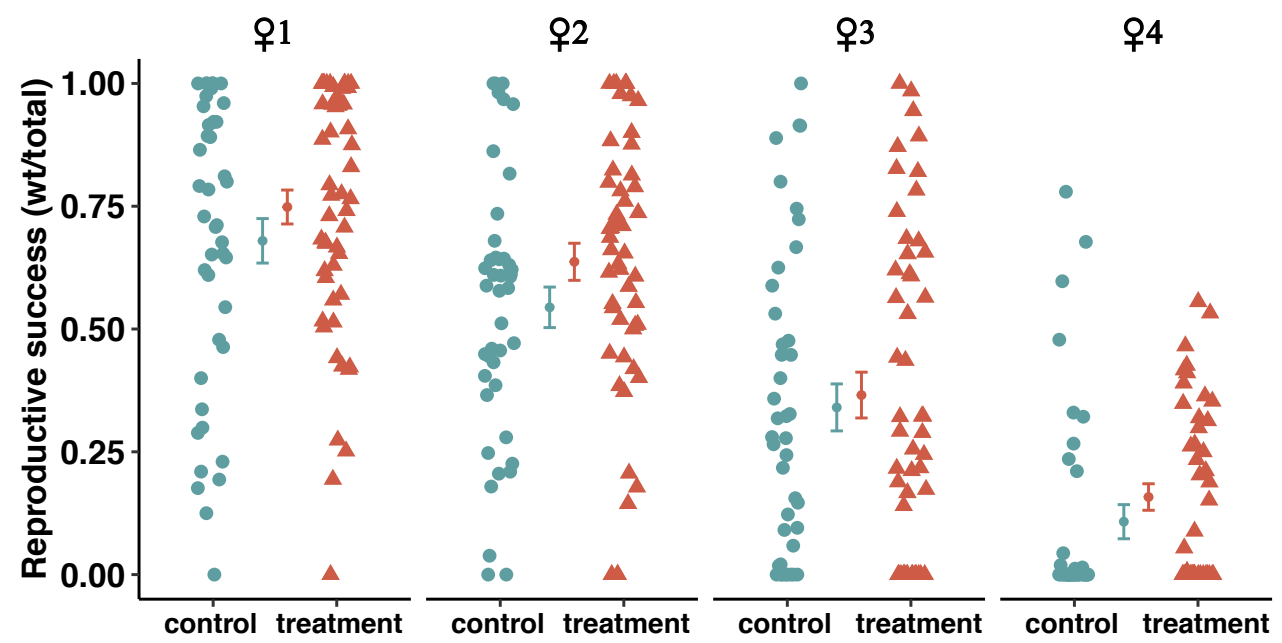

908 Supplementary 10. Mean relative reproductive success of control (green circles) vs treatment

909 (orange triangles) males over the first, second, third and fourth female males were presented to,

910 with the onset of male access to female manipulated to 1 day. Only males surviving to compete

911 over the corresponding female are represented (i.e. zero values show males accomplishing $0 \%$

912 reproductive success). Vertical bars represent the standard error around the mean. 
925 Supplementary 11: additional Material and Method with regards to computer model and

926 simulations

928 1. $k_{i}(x)=0$, for $x<\beta_{i}$, and $k_{i}(x)=\exp \left(u_{i}\right)$ for $x \geq \beta_{i}$, where $\beta_{i}$ is the age at first mate of the $i^{\text {th }}$ 929 individual.

$930 \quad$ 2. $\beta_{i}$ is assumed to be a random variable with

$$
\log \left(\beta_{i}\right) \sim N\left(\mu_{\llcorner\beta}, \sigma_{\llcorner\beta}\right)
$$

932 Note that the mean of $\beta_{i}$ increases with $\sigma_{L \beta}$, and conveniently, if $\mu_{\llcorner\beta}=\sigma_{L \beta}=0, \beta_{i}=1$ for any

933 individual. We computed $\mu_{\llcorner\beta}$ and $\sigma_{\llcorner\beta}$ from the parameters at the arithmetic scale, $\mu_{\beta}$ and $\sigma_{\beta}$.

934 3. For $x \geq \beta_{i}, u_{i}(x)$ is the summation of three components: elevation $\left(E_{i}\right)$, structural deviation $\left[A_{i}(x)\right]$

935 due to reproductive age, and individual (random) deviation within the effective reproductive period

$936\left(s_{i}\right)$. We used subscripts for $E$ and $A$ because they are assumed to be $\beta_{i}$-dependent (see below).

937 4. We modelled $E_{i}$ as a linear function of $\beta_{i}$ according to the relationships depicted in

938 supplementary 5 , that is,

$$
E_{i}=e_{0}+e_{1}\left(\beta_{i}\right)
$$

940 where $e_{0}$ and $e_{1}$ are the parameters of the linear relationships. Two scenarios are assumed: females 941 perception is conditioning the male response ("spendthrift" strategy, henceforth S strategy) or not

942 ("thrifty" strategy, henceforth $T$ strategy), and accordingly two pairs $\left\{\mathrm{e}_{0}, \mathrm{e}_{1}\right\}$ were be used.

943 5. $A_{i}(x)$ is a rotated sigmoid function of $x$ for $x \in\left[\beta_{i}, \omega[\right.$. We chose a simple (cubic) function based

944 on the inspection of the smooth functions found by GAM (Supplementary 4). Our function is a

945 linear modification of

$$
A_{i}^{\prime}\left(x^{\prime}\right)=b_{1}\left(x^{\prime}-c\right)+b_{3}\left(x^{\prime}-c\right)^{3},
$$

947 (core function) where $b_{1}$ and $b_{3}$ are the polynomial (negative) coefficients and $x^{\prime}$ ranges from 0 to 1.

948 When $x^{\prime}=c$ the function has its maximum slope $\left(=b_{1}\right)$. The equation is rescaled from $x^{\prime}$ to $x$, which 949 ranges from $\beta_{i}$ to $\omega$. By normalizing $A_{i}^{\prime}(x)$ so that it is centred to zero for $x \in\left[\beta_{i}, \omega\left[\right.\right.$, we obtain $A_{i}(x)$.

950 We used parameter values consistent with our empirical observations, giving priority to early ages, 951 since late ones are expected to have low effect on fitness.

952 6. $s_{i}$ is modeled as a random Gaussian slope for the relationship between $u_{i}$ and $x$, which accounts 953 for individual deviations from $A_{i}(x)$. That is, 
955 In summary, our model is

956

$957 k_{i}(x)=0$, for $x \in\left[0, \beta_{i}[\right.$,

958

$959 \log \left[k_{i}(x)\right]=$

$960 \mathrm{e}_{0}+\mathrm{e}_{1}\left(\beta_{\mathrm{i}}\right)$

$961+$

$\left.962 b_{1}\left(\left[x-\beta_{i}\right] /\left[\omega-\beta_{i}\right]-c\right)+b_{3}\left[x-\beta_{i}\right] /\left[\omega-\beta_{i}\right]-c\right)^{3}-$

$\left.9631 /\left[\omega-\beta_{i}\right] \int_{\beta i}{ }^{\omega} b_{1}\left(\left[y-\beta_{i}\right] /\left[\omega-\beta_{i}\right]-c\right)+b_{3}\left(y-\beta_{i}\right] /\left[\omega-\beta_{i}\right]-c\right)^{3} d y$

$964+$

$965 s_{i} x$,

966 for $x \in\left[\beta_{i}, \omega[\right.$ (y: age) ;

$967 \mathrm{~s}_{\mathrm{i}} \sim \mathrm{N}\left(0, \sigma_{\mathrm{s}}\right)$;

$968 \log \left(\beta_{i}\right) \sim N\left(\mu_{\llcorner\beta}, \sigma_{\llcorner\beta}\right)$. See supplementary 4 for parameter values used in computer simulations.

969

970

971

972

973

974

975

976

977

978

979

980

981

982

983 
bioRxiv preprint doi: https://doi.org/10.1101/2021.04.19.440494; this version posted April 21, 2021. The copyright holder for this preprint (which was not certified by peer review) is the author/funder, who has granted bioRxiv a license to display the preprint in perpetuity. It is made available under aCC-BY 4.0 International license.

984 Supplementary 12: Simulations output across daily population growth rate $(r:-0.1,0,0.1)$, mean

985 value of $\beta$ (from 1 to $15 \mathrm{~d}$ ), and standard deviation of $\beta\left(\sigma_{\beta}: 0.01,0.1,1 d\right.$ ).

\section{Effects on Male Fitness}

\section{Distribution of Perception of Females}

Assumed values for the model parameters if otherwise is not explicitally stated

Parameters assumed to be indenpendent of the occurrence of percetion effects:

$b_{1}, b_{3} \& c$ (parameters for the structural shape of the log-reproductive function, $u(x)$; see text): $\quad \begin{array}{llll}0.001 & 30 & 0.4\end{array}$

$\omega$ (end of the reproductive period; $d$ ):

45

$\sigma_{\mathrm{s}}$ (standard deviation for the random, individual, slope $\mathrm{u}(\mathrm{x})$ vs. $\mathrm{x}$ ): $\quad 0.045$

$r$ (daily growth rate): $\quad 0$

Linear coefficients (intercept and slope) for the effect of $\beta$ (first mate) on $u(x)$ :

Perception of females before $\beta$ :

No perception of females before $\beta$ :

$1.4-0.12$

$\sigma_{\beta}:$

Simulation sample size, $n$ :

Perception vs. No Perception)

for the mean of $\beta$

(r: 0; n: 10000)
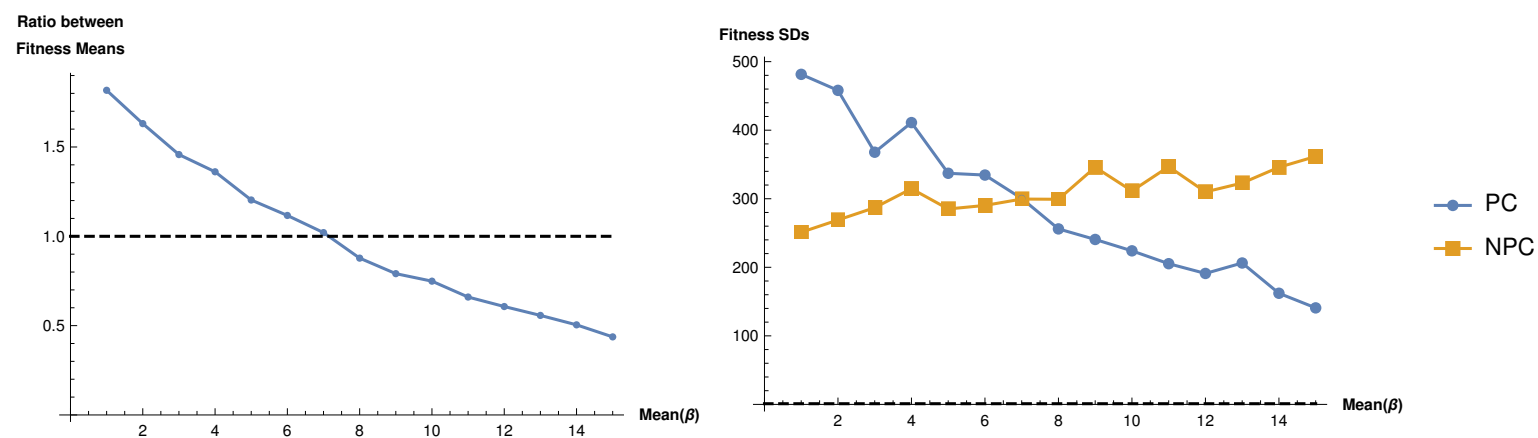

Interval of mean of $\beta$ for crossing at 1

Lower value: $\quad 7$

Upper value: $\quad 8$

Starting time:

DateObject[\{2020, 11, 18, 12, 38, 17.504462\}, Instant, Gregorian, 1.][]

Ending time: 
bioRxiv preprint doi: https://doi.org/10.1101/2021.04.19.440494; this version posted April 21, 2021. The copyright holder for this preprint (which was not certified by peer review) is the author/funder, who has granted bioRxiv a license to display the preprint in perpetuity. It is made available under aCC-BY 4.0 International license.

\section{Effects on Male Fitness}

\section{Distribution of Perception of Females}

Assumed values for the model parameters if otherwise is not explicitally stated

Parameters assumed to be indenpendent of the occurrence of percetion effects:

$b_{1}, b_{3} \& c$ (parameters for the structural shape of the log-reproductive function, $u(x)$; see text):

$\omega$ (end of the reproductive period; $d$ ):

45

$\sigma_{\mathrm{s}}$ (standard deviation for the random, individual, slope $\mathrm{u}(\mathrm{x}) \mathrm{vs.} \mathrm{x}$ ):

$r$ (daily growth rate):

Linear coefficients (intercept and slope) for the effect of $\beta$ (first mate) on $u(x)$ :

Perception of females before $\beta$ :

No perception of females before $\beta$ :

$\sigma_{\beta}:$

Perception vs. No Perception)

for the mean of $\beta$

(r: 0; n: 10000)
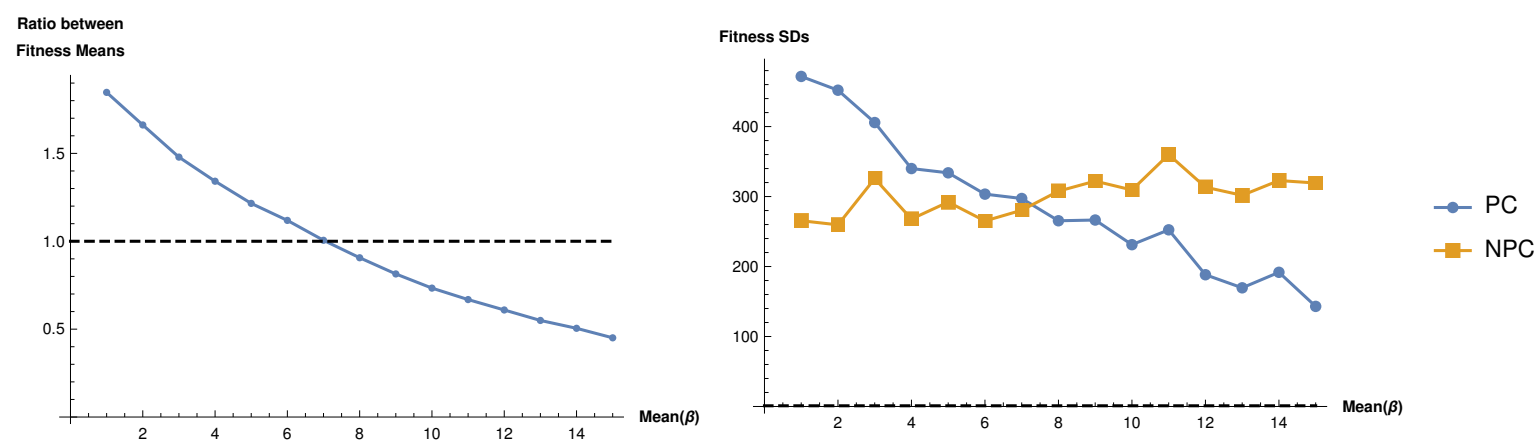

Interval of mean of $\beta$ for crossing at 1

Lower value:

7

Upper value:

8

Starting time:

DateObject[\{2020, 11, 14, 12, 42, 50.452728\}, Instant, Gregorian, 1.][]

Ending time: DateObject[\{2020, 11, 24, 15, 7, 13.912335\}, Instant, Gregorian, 1.][] 
bioRxiv preprint doi: https://doi.org/10.1101/2021.04.19.440494; this version posted April 21, 2021. The copyright holder for this preprint (which was not certified by peer review) is the author/funder, who has granted bioRxiv a license to display the preprint in perpetuity. It is made available under aCC-BY 4.0 International license.

\section{Effects on Male Fitness}

\section{Distribution of Perception of Females}

Assumed values for the model parameters if otherwise is not explicitally stated

Parameters assumed to be indenpendent of the occurrence of percetion effects:

$b_{1}, b_{3} \& c$ (parameters for the structural shape of the log-reproductive function, $u(x)$; see text):

$\omega$ (end of the reproductive period; $d$ ):

$0.001 \quad 30 \quad 0.4$

45

$\sigma_{\mathrm{s}}$ (standard deviation for the random, individual, slope $\mathrm{u}(\mathrm{x}) \mathrm{vs.} \mathrm{x}$ ):

0.045

$r$ (daily growth rate):

0

Linear coefficients (intercept and slope) for the effect of $\beta$ (first mate) on $u(x)$ :

Perception of females before $\beta$ :

$1.4-0.12$

No perception of females before $\beta$ :

$\sigma_{\beta}:$

0.1

Simulation sample size, $n$ :

10000

Perception vs. No Perception)

for the mean of $\beta$

(r: 0; n: 10000)

Ratio between

Fitness Means

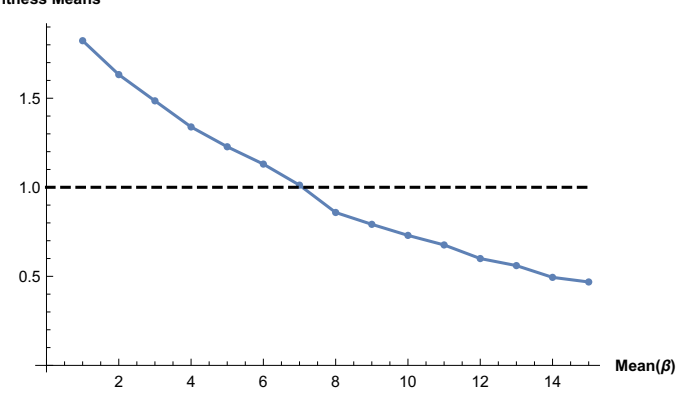

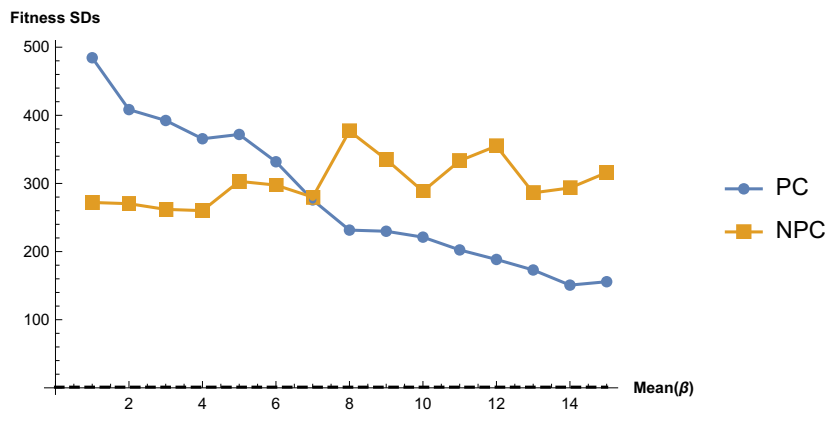

Interval of mean of $\beta$ for crossing at 1

Lower value:

Upper value:

Starting time:

Ending time:

\section{7}

8

DateObject[\{2020, 11, 18, 12, 52, 50.119123\}, Instant, Gregorian, 1.][]

DateObject[\{2020, 11, 23, 4, 41, 41.376258\}, Instant, Gregorian, 1.][] 
bioRxiv preprint doi: https://doi.org/10.1101/2021.04.19.440494; this version posted April 21, 2021. The copyright holder for this preprint (which was not certified by peer review) is the author/funder, who has granted bioRxiv a license to display the preprint in perpetuity. It is made available under aCC-BY 4.0 International license.

\section{Effects on Male Fitness}

\section{Distribution of Perception of Females}

Assumed values for the model parameters if otherwise is not explicitally stated

Parameters assumed to be indenpendent of the occurrence of percetion effects:

$b_{1}, b_{3} \& c$ (parameters for the structural shape of the log-reproductive function, $u(x)$; see text):

$\omega$ (end of the reproductive period; $d$ ):

45

$\sigma_{\mathrm{s}}$ (standard deviation for the random, individual, slope $\mathrm{u}(\mathrm{x}) \mathrm{vs.} \mathrm{x}$ ):

$r$ (daily growth rate):

Linear coefficients (intercept and slope) for the effect of $\beta$ (first mate) on $u(x)$ :

Perception of females before $\beta$ :

No perception of females before $\beta$ :

$\sigma_{\beta}:$

Perception vs. No Perception)

for the mean of $\beta$

(r: 0; n: 10000)
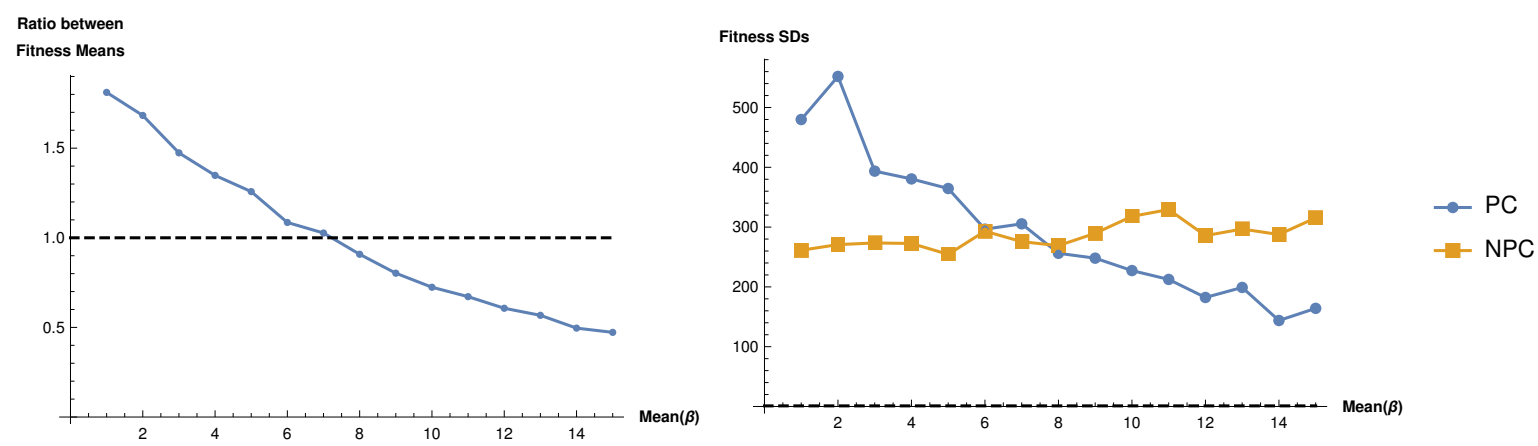

Interval of mean of $\beta$ for crossing at 1

Lower value:

7

Upper value:

8

Starting time:

DateObject[\{2020, 11, 14, 12, 43, 33.593780\}, Instant, Gregorian, 1.][]

Ending time:

DateObject[\{2020, 11, 24, 15, 2, 9.279470\}, Instant, Gregorian, 1.][] 
bioRxiv preprint doi: https://doi.org/10.1101/2021.04.19.440494; this version posted April 21, 2021. The copyright holder for this preprint (which was not certified by peer review) is the author/funder, who has granted bioRxiv a license to display the preprint in perpetuity. It is made available under aCC-BY 4.0 International license.

\section{Effects on Male Fitness}

\section{Distribution of Perception of Females}

Assumed values for the model parameters if otherwise is not explicitally stated

Parameters assumed to be indenpendent of the occurrence of percetion effects:

$b_{1}, b_{3} \& c$ (parameters for the structural shape of the log-reproductive function, $u(x)$; see text):

$\sigma_{\mathrm{s}}$ (standard deviation for the random, individual, slope $u(x)$ vs. $x$ ):

$r$ (daily growth rate):

Linear coefficients (intercept and slope) for the effect of $\beta$ (first mate) on $u(x)$ :

Perception of females before $\beta$ :

No perception of females before $\beta$ :

$\sigma_{\beta}:$

Simulation sample size, $n$ :
0.001

45

0.045

$30 \quad 0.4$

0

$1.4-0.12$

$0.7 \quad-0.02$

10000

Perception vs. No Perception)

for the mean of $\beta$

(r: 0; n: 10000)
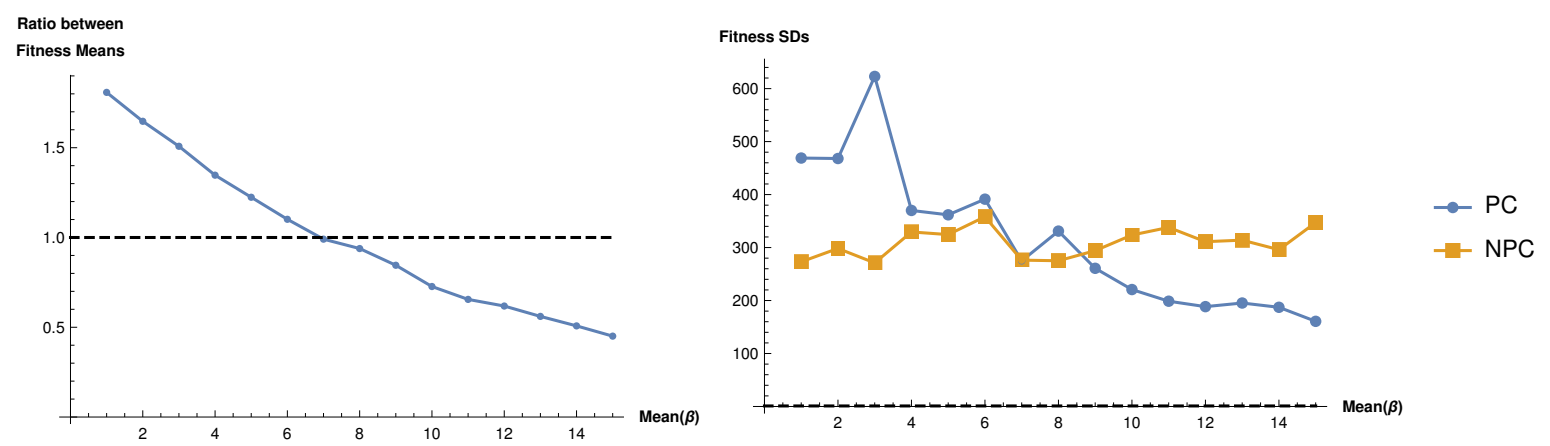

Interval of mean of $\beta$ for crossing at 1

Lower value:

6

Upper value:

7

Starting time:

DateObject[\{2020, 11, 24, 12, 21, 20.214004\}, Instant, Gregorian, 1.][]

Ending time:

DateObject[\{2020, 12, 4, 11, 21, 51.279001\}, Instant, Gregorian, 1.][] 
bioRxiv preprint doi: https://doi.org/10.1101/2021.04.19.440494; this version posted April 21, 2021. The copyright holder for this preprint (which was not certified by peer review) is the author/funder, who has granted bioRxiv a license to display the preprint in perpetuity. It is made available under aCC-BY 4.0 International license.

\section{Effects on Male Fitness}

\section{Distribution of Perception of Females}

Assumed values for the model parameters if otherwise is not explicitally stated

Parameters assumed to be indenpendent of the occurrence of percetion effects:

$b_{1}, b_{3} \& c$ (parameters for the structural shape of the log-reproductive function, $u(x)$; see text):

$\omega$ (end of the reproductive period; $d$ ):

$0.001 \quad 30 \quad 0.4$

45

$\sigma_{\mathrm{s}}$ (standard deviation for the random, individual, slope $\mathrm{u}(\mathrm{x}) \mathrm{vs.} \mathrm{x}$ ):

0.045

$r$ (daily growth rate):

0

Linear coefficients (intercept and slope) for the effect of $\beta$ (first mate) on $u(x)$ :

Perception of females before $\beta$ :

$1.4-0.12$

No perception of females before $\beta$ :

$\sigma_{\beta}:$

1

Simulation sample size, $n$ :

10000

Perception vs. No Perception)

for the mean of $\beta$

(r: 0; n: 10000)

Ratio between

Fitness Means

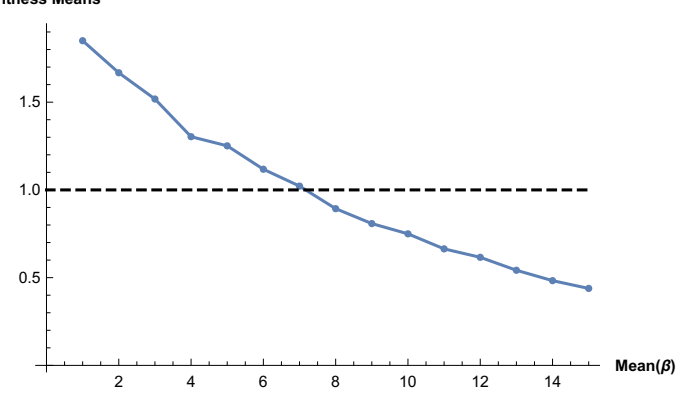

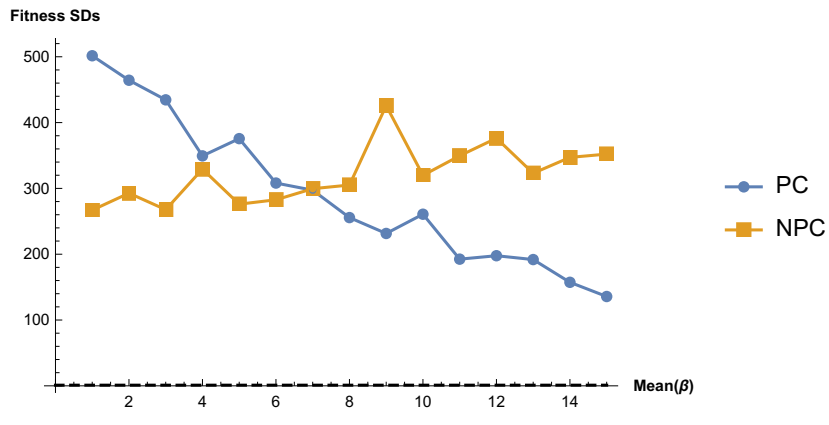

Interval of mean of $\beta$ for crossing at 1

Lower value:

Upper value:

Starting time:

Ending time:

\section{7}

8

DateObject[\{2020, 12, 5, 7, 44, 50.028010\}, Instant, Gregorian, 1.][]

DateObject[\{2020, 12, 10, 3, 59, 1.094242\}, Instant, Gregorian, 1.][] 
bioRxiv preprint doi: https://doi.org/10.1101/2021.04.19.440494; this version posted April 21, 2021. The copyright holder for this preprint (which was not certified by peer review) is the author/funder, who has granted bioRxiv a license to display the preprint in perpetuity. It is made available under aCC-BY 4.0 International license.

\section{Effects on Male Fitness}

\section{Distribution of Perception of Females}

Assumed values for the model parameters if otherwise is not explicitally stated

Parameters assumed to be indenpendent of the occurrence of percetion effects:

$b_{1}, b_{3} \& c$ (parameters for the structural shape of the log-reproductive function, $u(x)$; see text):

$\omega$ (end of the reproductive period; $d$ ):

45

$\sigma_{\mathrm{s}}$ (standard deviation for the random, individual, slope $\mathrm{u}(\mathrm{x}) \mathrm{vs.} \mathrm{x}$ ):

$r$ (daily growth rate):

Linear coefficients (intercept and slope) for the effect of $\beta$ (first mate) on $u(x)$ :

Perception of females before $\beta$ :

No perception of females before $\beta$ :

Perception vs. No Perception) for the mean of $\beta$

(r: 0.1;n: 10000)
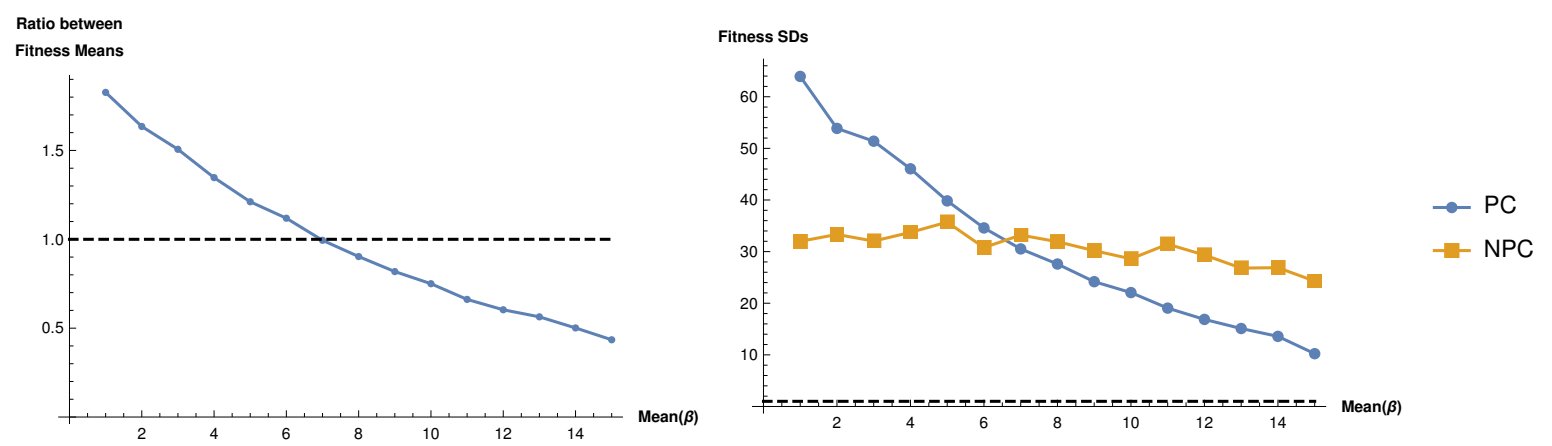

Interval of mean of $\beta$ for crossing at 1

Lower value:

Upper value:

7

Starting time:

DateObject[\{2020, 11, 18, 12, 39, 54.136700\}, Instant, Gregorian, 1.][]

Ending time:

DateObject[\{2020, 11, 28, 16, 39, 12.637336\}, Instant, Gregorian, 1.][] 
bioRxiv preprint doi: https://doi.org/10.1101/2021.04.19.440494; this version posted April 21, 2021. The copyright holder for this preprint (which was not certified by peer review) is the author/funder, who has granted bioRxiv a license to display the preprint in perpetuity. It is made available under aCC-BY 4.0 International license.

\section{Effects on Male Fitness}

\section{Distribution of Perception of Females}

Assumed values for the model parameters if otherwise is not explicitally stated

Parameters assumed to be indenpendent of the occurrence of percetion effects:

$b_{1}, b_{3} \& c$ (parameters for the structural shape of the log-reproductive function, $u(x)$; see text):

$\omega$ (end of the reproductive period; $d$ ):

45

$\sigma_{\mathrm{s}}$ (standard deviation for the random, individual, slope $\mathrm{u}(\mathrm{x})$ vs. $\mathrm{x}$ ):

Linear coefficients (intercept and slope) for the effect of $\beta$ (first mate) on $u(x)$ :

Perception of females before $\beta$ :

No perception of females before $\beta$ :

$\sigma_{\beta}:$

Perception vs. No Perception)

for the mean of $\beta$

(r: 0.1;n: 10000)
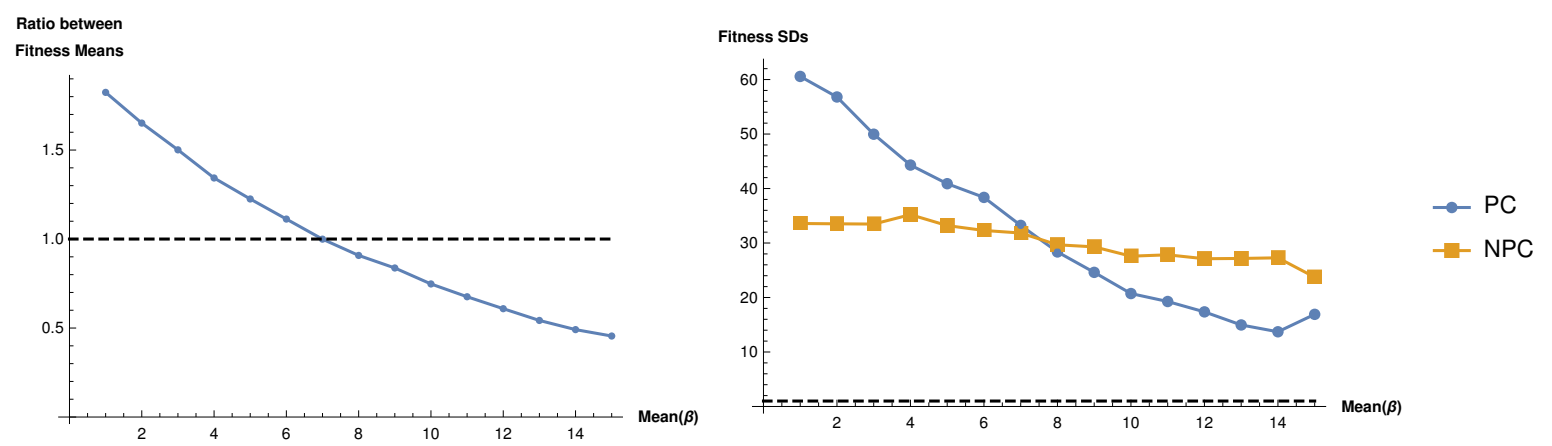

Interval of mean of $\beta$ for crossing at 1

Lower value:

6

Upper value:

7

Starting time:

DateObject[\{2020, 11, 14, 12, 46, 15.779300\}, Instant, Gregorian, 1.][]

Ending time:

DateObject[\{2020, 11, 24, 3, 19, 23.788838\}, Instant, Gregorian, 1.][] 
bioRxiv preprint doi: https://doi.org/10.1101/2021.04.19.440494; this version posted April 21, 2021. The copyright holder for this preprint (which was not certified by peer review) is the author/funder, who has granted bioRxiv a license to display the preprint in perpetuity. It is made available under aCC-BY 4.0 International license.

\section{Effects on Male Fitness}

\section{Distribution of Perception of Females}

Assumed values for the model parameters if otherwise is not explicitally stated

Parameters assumed to be indenpendent of the occurrence of percetion effects:

$b_{1}, b_{3} \& c$ (parameters for the structural shape of the log-reproductive function, $u(x)$; see text):

$\omega$ (end of the reproductive period; $d$ ):

$0.001 \quad 30 \quad 0.4$

45

$\sigma_{\mathrm{s}}$ (standard deviation for the random, individual, slope $\mathrm{u}(\mathrm{x}) \mathrm{vs.} \mathrm{x}$ ):

0.045

$r$ (daily growth rate):

0.1

Linear coefficients (intercept and slope) for the effect of $\beta$ (first mate) on $u(x)$ :

Perception of females before $\beta$ :

$1.4-0.12$

No perception of females before $\beta$ :

$\sigma_{\beta}:$

0.1

Simulation sample size, $n$ :

10000

Perception vs. No Perception)

for the mean of $\beta$

(r: 0.1; n: 10000)

Ratio between

Fitness Means

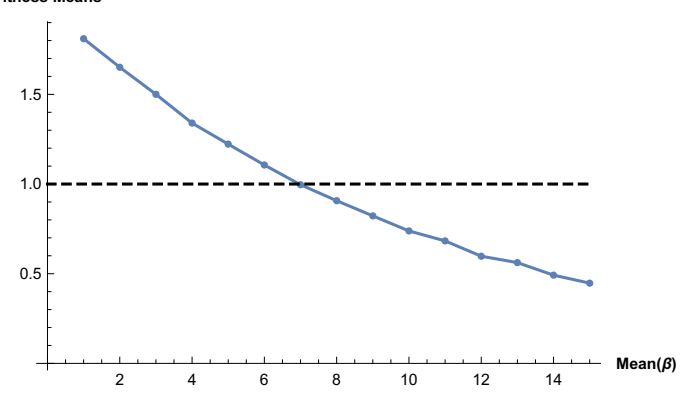

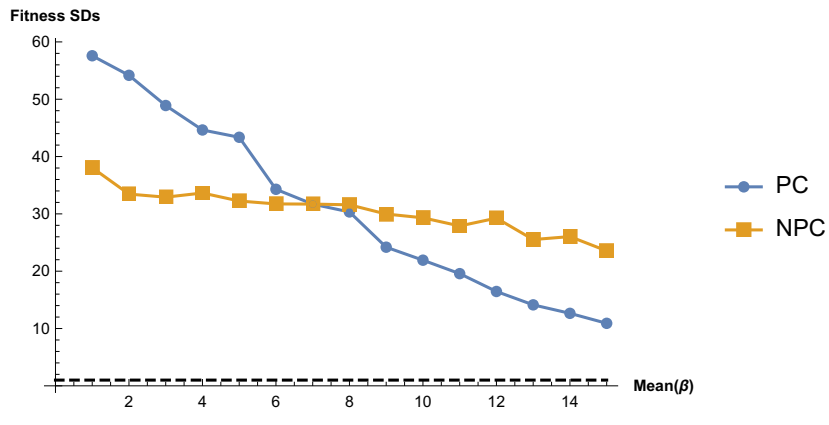

Interval of mean of $\beta$ for crossing at 1

Lower value:

6

Upper value:

7

Starting time:

DateObject[\{2020, 11, 23, 15, 26, 31.662040\}, Instant, Gregorian, 1.][]

Ending time:

DateObject[\{2020, 11, 28, 12, 8, 40.909292\}, Instant, Gregorian, 1.][] 
bioRxiv preprint doi: https://doi.org/10.1101/2021.04.19.440494; this version posted April 21, 2021. The copyright holder for this preprint (which was not certified by peer review) is the author/funder, who has granted bioRxiv a license to display the preprint in perpetuity. It is made available under aCC-BY 4.0 International license.

\section{Effects on Male Fitness}

\section{Distribution of Perception of Females}

Assumed values for the model parameters if otherwise is not explicitally stated

Parameters assumed to be indenpendent of the occurrence of percetion effects:

$b_{1}, b_{3} \& c$ (parameters for the structural shape of the log-reproductive function, $u(x)$; see text):

$\omega$ (end of the reproductive period; $d$ ):

45

$\sigma_{\mathrm{s}}$ (standard deviation for the random, individual, slope $\mathrm{u}(\mathrm{x}) \mathrm{vs.} \mathrm{x}$ ):

Linear coefficients (intercept and slope) for the effect of $\beta$ (first mate) on $u(x)$ :

Perception of females before $\beta$ :

No perception of females before $\beta$ :

$\sigma_{\beta}:$

Perception vs. No Perception)

for the mean of $\beta$

(r: $0.1 ; \mathrm{n}: 10000)$
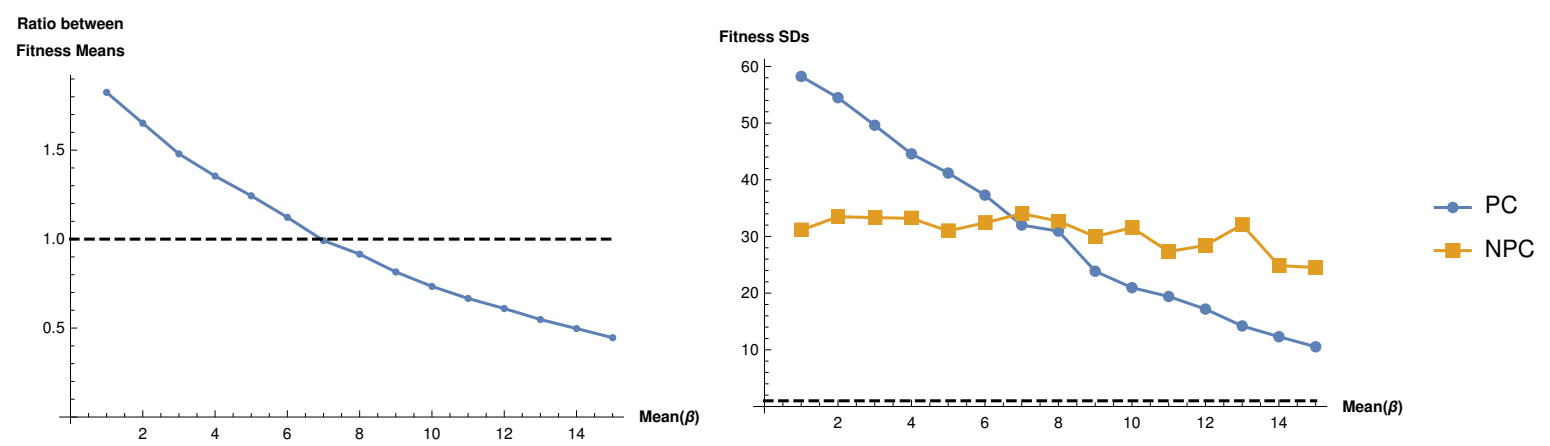

Interval of mean of $\beta$ for crossing at 1

Lower value:

6

Upper value:

7

Starting time:

DateObject[\{2020, 11, 14, 12, 46, 40.188345\}, Instant, Gregorian, 1.][]

Ending time: DateObject[\{2020, 11, 24, 17, 14, 33.271817\}, Instant, Gregorian, 1.][] 
bioRxiv preprint doi: https://doi.org/10.1101/2021.04.19.440494; this version posted April 21, 2021. The copyright holder for this preprint (which was not certified by peer review) is the author/funder, who has granted bioRxiv a license to display the preprint in perpetuity. It is made available under aCC-BY 4.0 International license.

\section{Effects on Male Fitness}

\section{Distribution of Perception of Females}

Assumed values for the model parameters if otherwise is not explicitally stated

Parameters assumed to be indenpendent of the occurrence of percetion effects:

$b_{1}, b_{3} \& c$ (parameters for the structural shape of the log-reproductive function, $u(x)$; see text):

$\omega$ (end of the reproductive period; $d$ ):

45

$\sigma_{\mathrm{s}}$ (standard deviation for the random, individual, slope $\mathrm{u}(\mathrm{x})$ vs. $\mathrm{x}$ ):

$r$ (daily growth rate):

Linear coefficients (intercept and slope) for the effect of $\beta$ (first mate) on $u(x)$ :

Perception of females before $\beta$ :

No perception of females before $\beta$ :

$\sigma_{\beta}:$

Perception vs. No Perception)

for the mean of $\beta$

(r: $0.1 ; \mathrm{n}: 10000)$
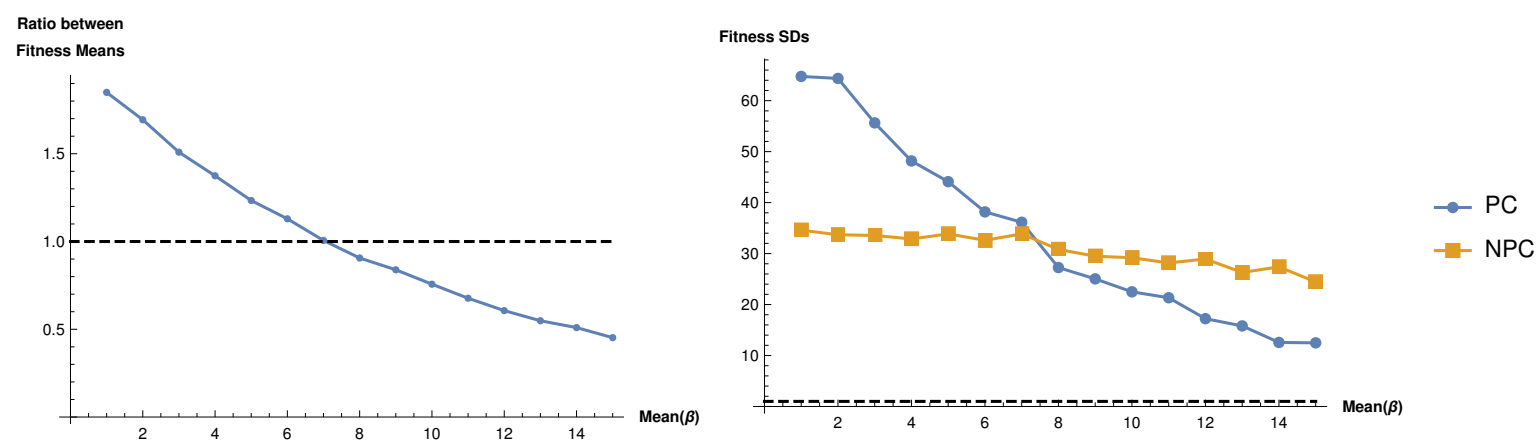

Interval of mean of $\beta$ for crossing at 1

Lower value:

7

Upper value:

8

Starting time:

DateObject[\{2020, 11, 27, 12, 43, 3.742819\}, Instant, Gregorian, 1.][]

Ending time: DateObject[\{2020, 12, 7, 10, 44, 41.810293\}, Instant, Gregorian, 1.][] 
bioRxiv preprint doi: https://doi.org/10.1101/2021.04.19.440494; this version posted April 21, 2021. The copyright holder for this preprint (which was not certified by peer review) is the author/funder, who has granted bioRxiv a license to display the preprint in perpetuity. It is made available under aCC-BY 4.0 International license.

\section{Effects on Male Fitness}

\section{Distribution of Perception of Females}

Assumed values for the model parameters if otherwise is not explicitally stated

Parameters assumed to be indenpendent of the occurrence of percetion effects:

$b_{1}, b_{3} \& c$ (parameters for the structural shape of the log-reproductive function, $u(x)$; see text):

$\omega$ (end of the reproductive period; $d$ ):

45

$\sigma_{\mathrm{s}}$ (standard deviation for the random, individual, slope $\mathrm{u}(\mathrm{x}) \mathrm{vs.} \mathrm{x}$ ):

$r$ (daily growth rate):

Linear coefficients (intercept and slope) for the effect of $\beta$ (first mate) on $u(x)$ :

Perception of females before $\beta$ :

No perception of females before $\beta$ :

$\sigma_{\beta}:$

1

Simulation sample size, $n$ :

10000

Perception vs. No Perception)

for the mean of $\beta$

(r: 0.1;n: 10000)
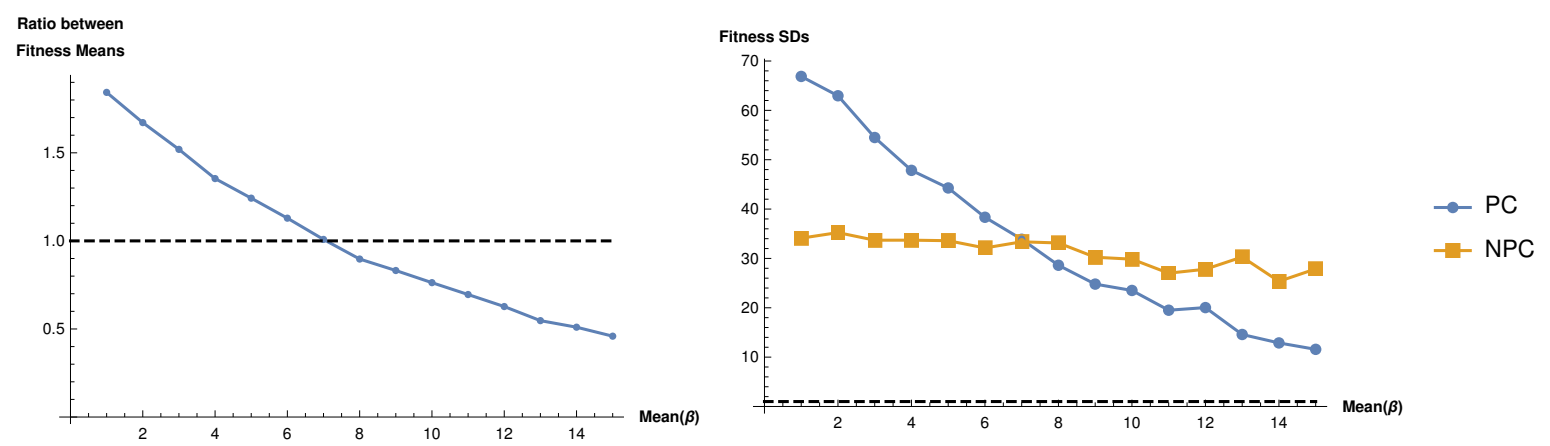

Interval of mean of $\beta$ for crossing at 1

Lower value:

7

Upper value:

8

Starting time:

DateObject[\{2020, 11, 27, 12, 46, 30.312152\}, Instant, Gregorian, 1.][]

Ending time:

DateObject[\{2020, 12, 7, 12, 38, 24.690763\}, Instant, Gregorian, 1.][] 
bioRxiv preprint doi: https://doi.org/10.1101/2021.04.19.440494; this version posted April 21, 2021. The copyright holder for this preprint (which was not certified by peer review) is the author/funder, who has granted bioRxiv a license to display the preprint in perpetuity. It is made available under aCC-BY 4.0 International license.

\section{Effects on Male Fitness}

\section{Distribution of Perception of Females}

Assumed values for the model parameters if otherwise is not explicitally stated

Parameters assumed to be indenpendent of the occurrence of percetion effects:

$b_{1}, b_{3} \& c$ (parameters for the structural shape of the log-reproductive function, $u(x)$; see text):

$\omega$ (end of the reproductive period; $d$ ):

$0.001 \quad 30 \quad 0.4$

45

0.045

$r$ (daily growth rate):

$-0.1$

Linear coefficients (intercept and slope) for the effect of $\beta$ (first mate) on $u(x)$ :

Perception of females before $\beta$ :

No perception of females before $\beta$ :

$\sigma_{\beta}:$

0.1

Simulation sample size, $n$ :

10000

Perception vs. No Perception)

for the mean of $\beta$

(r: $-0.1 ; \mathrm{n}: 10000)$

Ratio between

Fitness Means

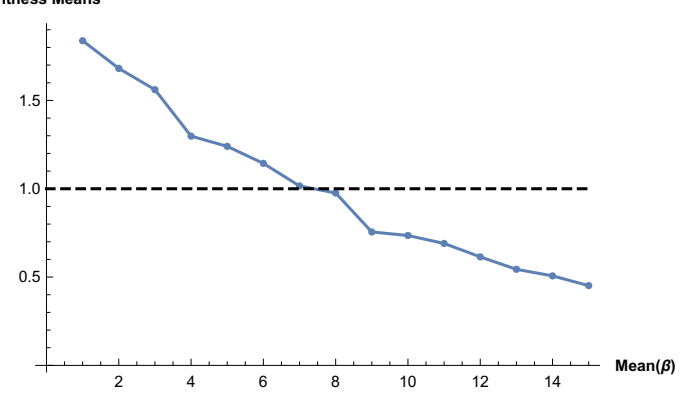

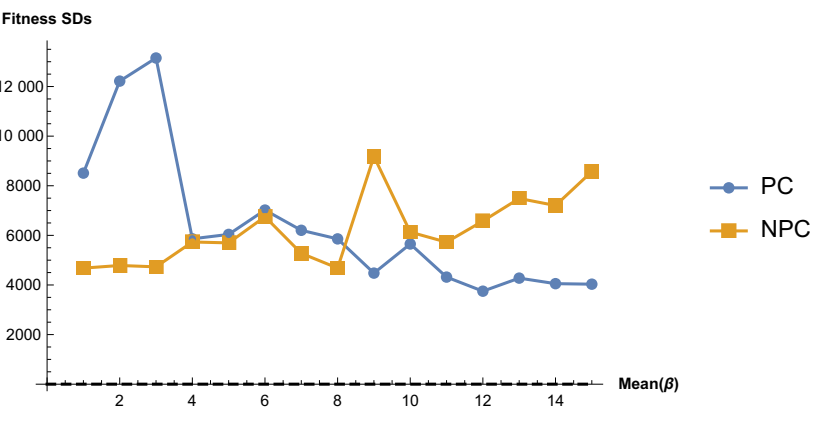

Interval of mean of $\beta$ for crossing at 1

Lower value:

Upper value:

Starting time:

Ending time:

\section{7}

8

DateObject[\{2020, 12, 4, 21, 29, 35.587682\}, Instant, Gregorian, 1.][]

DateObject[\{2020, 12, 9, 16, 39, 5.438685\}, Instant, Gregorian, 1.][] 
bioRxiv preprint doi: https://doi.org/10.1101/2021.04.19.440494; this version posted April 21, 2021. The copyright holder for this preprint (which was not certified by peer review) is the author/funder, who has granted bioRxiv a license to display the preprint in perpetuity. It is made available under aCC-BY 4.0 International license.

\section{Effects on Male Fitness}

\section{Distribution of Perception of Females}

Assumed values for the model parameters if otherwise is not explicitally stated

Parameters assumed to be indenpendent of the occurrence of percetion effects:

$\mathrm{b}_{1}, \mathrm{~b}_{3} \& \mathrm{c}$ (parameters for the structural shape of the log-reproductive function, $\mathrm{u}(\mathrm{x})$; see text):

$\omega$ (end of the reproductive period; $d$ ):

$0.001 \quad 30 \quad 0.4$

45

0.045

$r$ (daily growth rate):

$-0.1$

Linear coefficients (intercept and slope) for the effect of $\beta$ (first mate) on $u(x)$ :

Perception of females before $\beta$ :

No perception of females before $\beta$ :

$\sigma_{\beta}:$

0.01

Simulation sample size, $n$ :

10000

Perception vs. No Perception)

for the mean of $\beta$

(r: $-0.1 ; \mathrm{n}: 10000)$

Ratio between

Fitness Means

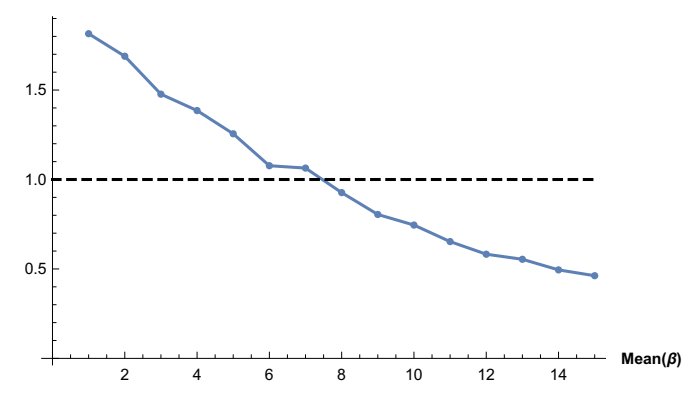

Interval of mean of $\beta$ for crossing at 1

Lower value:

Upper value:

Starting time:

Ending time:

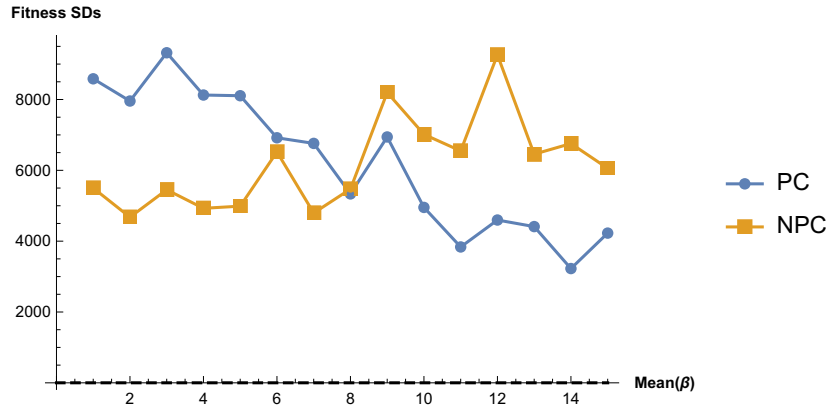

DateObject[\{2020, 11, 7, 17, 9, 36.327927\}, Instant, Gregorian, 1.][]

DateObject[\{2020, 11, 12, 2, 5, 48.294566\}, Instant, Gregorian, 1.][] 
bioRxiv preprint doi: https://doi.org/10.1101/2021.04.19.440494; this version posted April 21, 2021. The copyright holder for this preprint (which was not certified by peer review) is the author/funder, who has granted bioRxiv a license to display the preprint in perpetuity. It is made available under aCC-BY 4.0 International license.

\section{Effects on Male Fitness}

\section{Distribution of Perception of Females}

Assumed values for the model parameters if otherwise is not explicitally stated

Parameters assumed to be indenpendent of the occurrence of percetion effects:

$b_{1}, b_{3} \& c$ (parameters for the structural shape of the log-reproductive function, $u(x)$; see text):

$\omega$ (end of the reproductive period; $d$ ):

$0.001 \quad 30 \quad 0.4$

45

0.045

$r$ (daily growth rate):

$-0.1$

Linear coefficients (intercept and slope) for the effect of $\beta$ (first mate) on $u(x)$ :

Perception of females before $\beta$ :

No perception of females before $\beta$ :

$\sigma_{\beta}:$

Simulation sample size, $n$ :

Perception vs. No Perception)

for the mean of $\beta$

(r: $-0.1 ; n: 10000)$
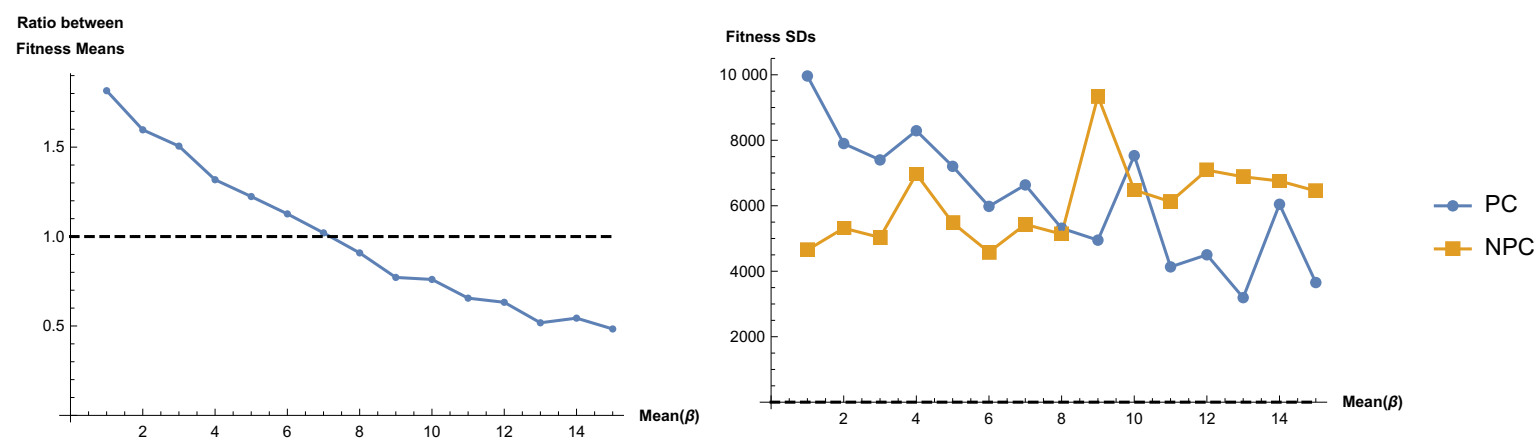

Interval of mean of $\beta$ for crossing at 1

Lower value:

7

Upper value:

8

Starting time:

DateObject[\{2020, 11, 18, 12, 50, 39.207186\}, Instant, Gregorian, 1.][]

Ending time: 
bioRxiv preprint doi: https://doi.org/10.1101/2021.04.19.440494; this version posted April 21, 2021. The copyright holder for this preprint

(which was not certified by peer review) is the author/funder, who has granted bioRxiv a license to display the preprint in perpetuity. It is made available under aCC-BY 4.0 International license.

\section{Effects on Male Fitness}

\section{Distribution of Perception of Females}

Assumed values for the model parameters if otherwise is not explicitally stated

Parameters assumed to be indenpendent of the occurrence of percetion effects:

$b_{1}, b_{3} \& c$ (parameters for the structural shape of the log-reproductive function, $u(x)$; see text):

$\omega$ (end of the reproductive period; $d$ ):

$\sigma_{\mathrm{s}}$ (standard deviation for the random, individual, slope $\mathrm{u}(\mathrm{x}) \mathrm{vs} . \mathrm{x}$ ):

$r$ (daily growth rate):

Linear coefficients (intercept and slope) for the effect of $\beta$ (first mate) on $u(x)$ :

Perception of females before $\beta$ :

No perception of females before $\beta$ :

$\sigma_{\beta}$ :

Simulation sample size, $n$ :
0.001

45

$-0.1$

$30 \quad 0.4$

$\begin{array}{ll}1.4 & -0.12 \\ 0.7 & -0.02 \\ 0.01 & \end{array}$

10000

Perception vs. No Perception)

for the mean of $\beta$

(r: $-0.1 ; n: 10000)$
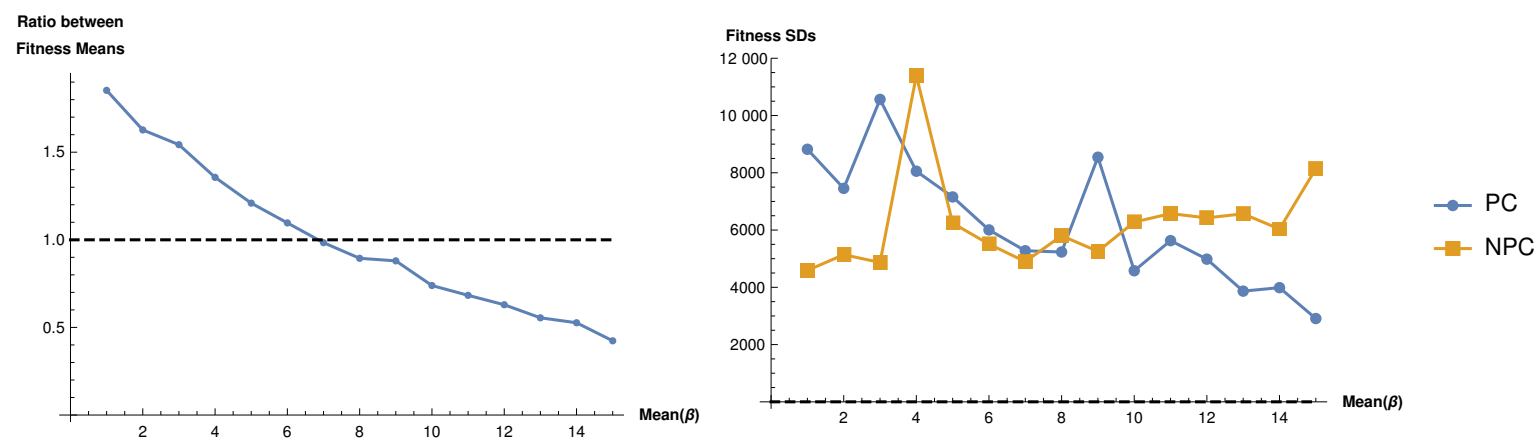

Interval of mean of $\beta$ for crossing at 1

Lower value:

6

Upper value:

7

Starting time:

DateObject[\{2020, 11, 14, 12, 40, 54.227991\}, Instant, Gregorian, 1.][]

Ending time:

DateObject[\{2020, 11, 24, 18, 43, 28.451502\}, Instant, Gregorian, 1.][] 
bioRxiv preprint doi: https://doi.org/10.1101/2021.04.19.440494; this version posted April 21, 2021. The copyright holder for this preprint (which was not certified by peer review) is the author/funder, who has granted bioRxiv a license to display the preprint in perpetuity. It is made available under aCC-BY 4.0 International license.

\section{Effects on Male Fitness}

\section{Distribution of Perception of Females}

Assumed values for the model parameters if otherwise is not explicitally stated

Parameters assumed to be indenpendent of the occurrence of percetion effects:

$b_{1}, b_{3} \& c$ (parameters for the structural shape of the log-reproductive function, $u(x)$; see text):

$\omega$ (end of the reproductive period; $d$ ):

$0.001 \quad 30 \quad 0.4$

45

0.045

$r$ (daily growth rate):

$-0.1$

Linear coefficients (intercept and slope) for the effect of $\beta$ (first mate) on $u(x)$ :

Perception of females before $\beta$ :

$1.4-0.12$

No perception of females before $\beta$ :

$\sigma_{\beta}:$

1

Simulation sample size, $n$ :

Perception vs. No Perception)

for the mean of $\beta$

(r: $-0.1 ; n: 10000)$

Ratio between

Fitness Means

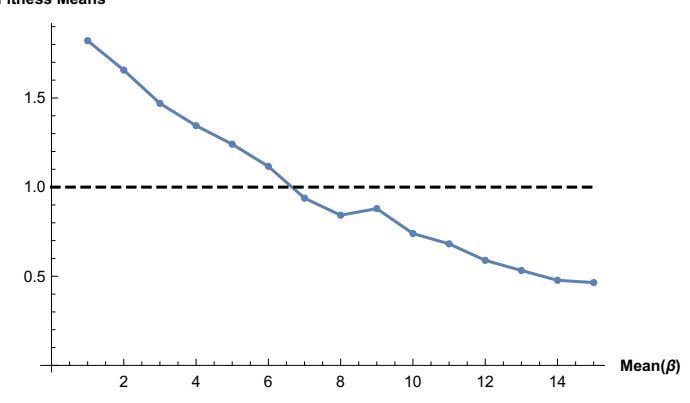

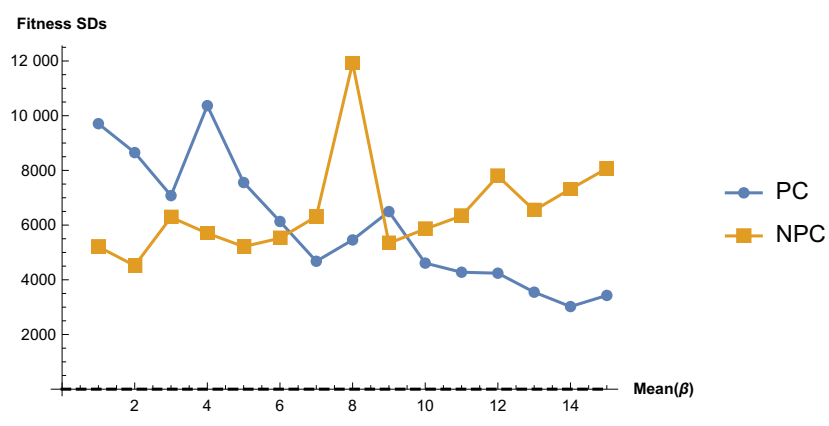

Interval of mean of $\beta$ for crossing at 1

Lower value:

Upper value:

Starting time:

Ending time:
6

7

DateObject[\{2020, 11, 23, 15, 29, 51.648261\}, Instant, Gregorian, 1.][]

DateObject[\{2020, 11, 28, 14, 55, 43.895027\}, Instant, Gregorian, 1.][] 
bioRxiv preprint doi: https://doi.org/10.1101/2021.04.19.440494; this version posted April 21, 2021. The copyright holder for this preprint (which was not certified by peer review) is the author/funder, who has granted bioRxiv a license to display the preprint in perpetuity. It is made available under aCC-BY 4.0 International license.

\section{Effects on Male Fitness}

\section{Distribution of Perception of Females}

Assumed values for the model parameters if otherwise is not explicitally stated

Parameters assumed to be indenpendent of the occurrence of percetion effects:

$\mathrm{b}_{1}, \mathrm{~b}_{3} \& \mathrm{c}$ (parameters for the structural shape of the log-reproductive function, $\mathrm{u}(\mathrm{x})$; see text):

$\omega$ (end of the reproductive period; $d$ ):

$0.001 \quad 30 \quad 0.4$

45

0.045

$r$ (daily growth rate):

$-0.1$

Linear coefficients (intercept and slope) for the effect of $\beta$ (first mate) on $u(x)$ :

Perception of females before $\beta$ :

$1.4-0.12$

No perception of females before $\beta$ :

$\sigma_{\beta}:$

1

Simulation sample size, $n$ :

10000

Perception vs. No Perception)

for the mean of $\beta$

(r: $-0.1 ; n: 10000$ )

Ratio between

Fitness Means

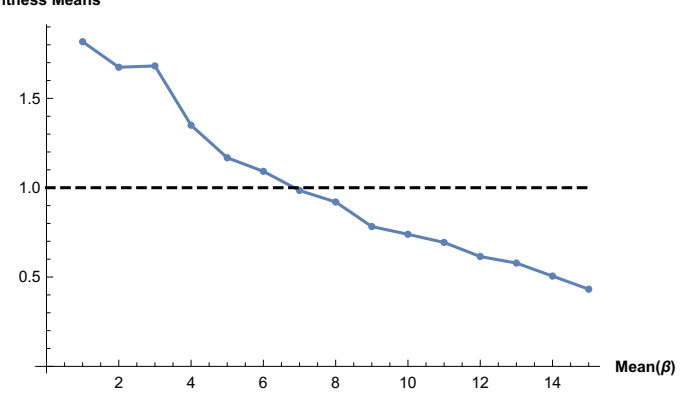

Interval of mean of $\beta$ for crossing at 1

Lower value:

6

Upper value:

Starting time:

Ending time:

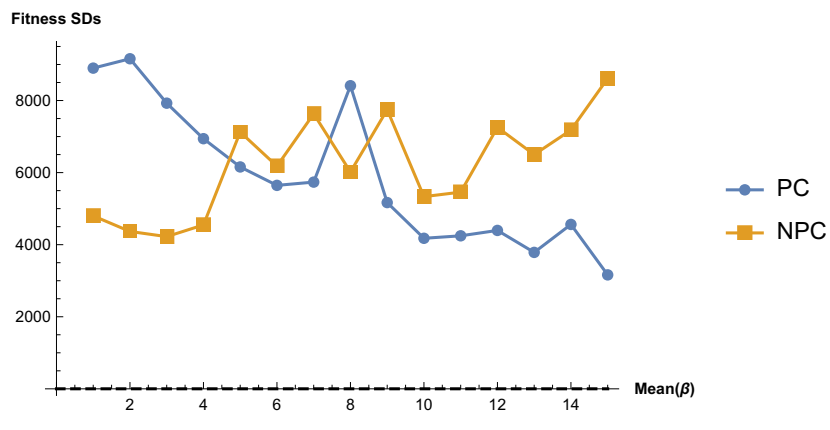

